\title{
Energy deprivation-induced AMPK activation inhibits milk synthesis by targeting PrIR and PGC-1a
}

\author{
Zhihui Wu' ${ }^{1}$, Qihui Li ${ }^{1}$, Siwang Yang ${ }^{1}$, Tenghui Zheng ${ }^{1}$, Jiayuan Shao ${ }^{1}$, Wutai Guan ${ }^{1,2,3}$, Fang Chen ${ }^{1,2,3^{*}}$ and \\ Shihai Zhang ${ }^{1,2,3^{*}}$ (D)
}

\begin{abstract}
Background: The mammary gland is responsible for milk production and secretion, which is critical for neonatal health during lactation. Lactation efficiency is largely affected by energy status with unclear mechanism.

Results: In the current study, we found that synthesis of milk fat and protein was significantly inhibited under energy-deficient conditions, which is accompanied with AMP-activated protein kinase (AMPK) activation. Modulating the AMPK signaling pathway directly or indirectly affects the synthesis of milk fat and protein. Besides mammalian target of rapamycin complex 1 (mTORC1) signaling in the regulation of milk synthesis, we discovered that AMPK mainly regulates the synthesis of milk protein through prolactin signaling. Mechanistically, AMPK triggers the ubiquitination of prolactin receptor (PrIR) through regulating the activity of $\beta$-transducin repeat-containing protein ( $\beta$ - $\operatorname{TrCP}$, an E3 ligase). Subsequently, PrIR is degraded by the endocytosis process of lysosomes, which further attenuates prolactin signaling. In addition, our results revealed that AMPK activation inhibits milk fat synthesis through decreasing and accelerating de novo synthesis and $\beta$-oxidation of fatty acids, respectively. To be precise, AMPK activation inhibits rate limiting enzymes and transcriptional regulatory factors involved in de novo fatty acid synthesis and decreases the acetylation process of peroxisome proliferator-activated receptor gamma coactivator-1 alpha (PGC-1a) to strengthen the oxidation of fatty acids.
\end{abstract}

Conclusions: Taken together, AMPK regulates the synthesis of milk not only depends on canonical mTORC1 signaling and key rate-limiting enzymes, but also through manipulating the degradation of PrIR and the acetylation of PGC-1a.

Keywords: AMPK, Mammary epithelial cells, Milk protein, Milk fat, PrIR, PGC-1a

\section{Background}

The mammary gland is the hallmark of mammals, which is involved in the process of milk synthesis. The nutritional property of maternal milk determines the neonatal growth and health outcomes during breastfeeding. Maternal nutrients not only supply substrates but also

\footnotetext{
*Correspondence: chenfang1111@scau.edu.cn; zhangshihai@scau.edu.cn ${ }^{1}$ Guangdong Province Key Laboratory of Animal Nutrition Control, College of Animal Science, South China Agricultural University, Guangzhou 510642, China

Full list of author information is available at the end of the article
}

provide large amounts of energy for the guarantee of milk synthesis [1]. During early lactation, maternal nutrition intake is usually insufficient to meet the requirement for milk secretion, which leads to a state called 'negative energy balance'. As a crucial sensor for cellular energy level, AMP-activated protein kinase (AMPK) is activated during the decrease of cellular ATP and the increase of ADP and AMP under energy stress. In addition, AMPK is also activated by the absence of fructose-1,6-bisphosphate (FBP), which is a metabolite of glucose [2]. Preliminary evidence indicated that once activated, AMPK attenuates milk synthesis through the inhibition of original author(s) and the source, provide a link to the Creative Commons licence, and indicate if changes were made. The images or other third party material in this article are included in the article's Creative Commons licence, unless indicated otherwise in a credit line to the material. If material is not included in the article's Creative Commons licence and your intended use is not permitted by statutory regulation or exceeds the permitted use, you will need to obtain permission directly from the copyright holder. To view a copy of this licence, visit http://creativecommons.org/licenses/by/4.0/. The Creative Commons Public Domain Dedication waiver (http://creativeco mmons.org/publicdomain/zero/1.0/) applies to the data made available in this article, unless otherwise stated in a credit line to the data. 
enzymes that directly participate in the synthesis of milk fat [3] and milk protein $[4,5]$. However, whether AMPK regulates milk synthesis through other critical enzymes or pathways remains largely unknown.

Mammary epithelial cells control milk fat level by balancing fatty acids synthesis and their degradation through $\beta$-oxidation system. Current studies mainly focus on the processes of de novo fatty acid (FA) synthesis, which includes FA uptake, activation, intracellular transport, elongation and desaturation, as well as triacylglycerol (TAG) synthesis and lipid droplet formation [6]. A number of rate-limiting enzymes of de novo fatty acid synthesis have been identified as the downstream targets of AMPK, such as acetyl-coA carboxylase alpha (ACACA) (phosphorylation site is S79) and sterol regulatory element-binding protein 1c (SREBP1c) (phosphorylation site is Ser372). ACACA catalyzes the conversion of acetyl-CoA to malonylCoA and initiates de novo FA synthesis [7]. SREBP1c is a transcription factor for lipid homeostasis, which regulates milk fat synthesis in cows [8], goats [9] and swine [10]. Currently, whether AMPK regulates milk fat synthesis through $\beta$-oxidation system remains less well understood.

Milk protein synthesis is mainly regulated by the process of gene transcription and protein translation. Mammalian target of rapamycin (mTOR) is a master regulator that promotes anabolic process. Previously, mTOR complex 1 (mTORC1) has been identified to control gene transcription and protein translation through regulating its two downstream molecules including ribosomal protein S6 kinase 1 (S6K1) and 4E binding protein 1 (4EBP1). In the mammary epithelial cells of rats [11] and cows [4], inhibition of mTORC1 activity could downregulate the mRNA expression of genes encoding milk proteins such as alphaS1-casein (CSN1S1) and betacasein (CSN2) and the process of milk protein translation [5]. Currently, how AMPK regulates milk protein through mTORC1-independent pathway (such as JAK2STAT5) remains largely unknown.

In our current study, we confirmed that AMPK regulates the synthesis of milk partially through the activation of mTORC1 signaling and expression of rate limiting enzymes. Importantly, we identified prolactin receptor (PrlR) and peroxisome proliferator-activated receptorC coactivator-1 alpha (PGC- $1 \alpha)$ as novel potential targets of AMPK to regulate milk protein and fat synthesis, respectively. We further found that AMPK induces the activity of $\beta-\operatorname{TrCP}$, which leads to the ubiquitination of PrlR and disruption of the prolactin signaling. AMPK promotes the $\beta$-oxidation of milk fatty acids through regulating the acetylation of PGC- $1 \alpha$. Taken together, we identified a novel molecular mechanism that AMPK regulates the synthesis of milk not only depends on canonical mTORC1 signaling and key rate-limiting enzymes, but also through manipulating the degradation of PrlR and the acetylation of PGC- $1 \alpha$.

\section{Materials and methods Cell cultures}

HC11 (mouse mammary epithelial cells) used in this study was first cultured in DMEM/F12 medium (Thermo) containing 10\% FBS (fetal bovine serum), 0.4\% HS (hydrocortisone), 0.4\% EGF (epidermal growth factor), $0.4 \%$ ITS (Insulin-Transferrin-Selenium) and 1\% PS (penicillin-streptomycin) in a cell incubator at 37 ${ }^{\circ} \mathrm{C}$ and $5 \% \mathrm{CO}_{2}$ concentration. When the cells reached to around $80 \%$ confluence, they were seeded in culture plates and incubated with the same medium and conditions. When the cells in culture plates reach to approximately $80 \%$ confluence again, medium were changed to DMEM/F12 glucose-free medium (Thermo). This step was mainly to deplete the glucose in the cells for subsequent experiments. After $4 \mathrm{~h}$-starvation treatment, cells were assigned into treatment mediums and harvested after $12 \mathrm{~h}$ and $24 \mathrm{~h}$ for real-time PCR and western-blotting, respectively. The reagents used in this experiment (mainly inhibitors or activators of pathways) are listed in Table 1.

\section{RNA-Seq analysis}

Total RNA was extracted using Trizol reagent kit (Invitrogen, Carlsbad, CA, USA) according to the manufacturer's protocol. The DNA libraries were sequenced on the Illumina sequencing platform by Genedenovo Biotechnology Co., Ltd (Guangzhou, China).

Table 1 Reagents for this experiment

\begin{tabular}{lll}
\hline Reagent & Company & Cat No \\
\hline AICAR & Sigma & A9978 \\
Phenformin hydrochloride & Sigma & P7045 \\
Compound C & Sigma & 171261 \\
Rapamycin & Sigma & V900930 \\
Pitstop & Sigma & SML1169 \\
EIPA & Sigma & 3378 \\
MG132 & Sigma & M8699 \\
MA & Sigma & M9281 \\
SB203580 & Sigma & HY-10256 \\
\hline
\end{tabular}




\section{Lipidomics}

After the cells were processed, they were scraped and collected with PBS. The subsequent operations and data processing were completed under the technical guidance and assistance of Novogene Co., Ltd. (Beijing, China).

\section{siRNA transfection}

The siRNA and other reagents used in this experiment were provided by RiboBio (China), and our operation was in accordance with the instructions provided by them. We first selected the one with the highest transfection efficiency from the 3 siRNA products provided by the company, and then used it for subsequent formal experiments.

\section{Oil red $O$ staining of lipid droplets}

To observe the production of milk fat more intuitively, oil red O staining solution (Sangon Bio, Shanghai) was used to observe the lipid droplets. In this experiment, the oil red dye solution used was diluted with double distilled water in a ratio of $6: 4$, and then filtered through 45-nm filters for 3 to 5 times before it can be used as a working solution. The cells were seeded into 24-well plates and cultured according to the methods mentioned above. They were harvested $24 \mathrm{~h}$ after being treated with the treatment medium for oil red staining. In brief, the cells were rinsed 3 times with PBS and fixed with $4 \%$ paraformaldehyde for $30 \mathrm{~min}$ at room temperature. Then, fresh working solution was added to cells $(200 \mu \mathrm{L}$ per well) followed by rinse with PBS twice. After $6 \mathrm{~h}$ of incubation at room temperature, cells were rinsed with PBS until there were no visible pellets before being observed and photographed under a microscope.

\section{Measurement of triacylglyceride concentration}

For quantitative estimation of the synthesis of intracellular and extracellular triacylglyceride, Triglyceride Assay Kit (Nanjing jiancheng, China) was used to detect the concentration of triacylglyceride in this research. The cells were seeded into 12 -well plates and cultured as described previously and collected $24 \mathrm{~h}$ after being treated with the treatment medium for triacylglyceride determination. Briefly, $100 \mu \mathrm{L}$ of medium from each well was collected uniformly for the subsequent determination of extracellular triacylglyceride. After rinsing with PBS, $50 \mu \mathrm{L}$ of RIPA lysis buffer containing 1\% PMSF and 1\% phosphatase inhibitor was added to each well. After lysis on ice for around $15 \mathrm{~min}$, the mixture in the well was collected as the samples for the subsequent determination of intracellular
Table 2 Antibodies for this experiment

\begin{tabular}{|c|c|c|c|}
\hline Antibody & Company & Cat No & Dilution \\
\hline FASN & Abcam & ab99539 & $1: 1000$ \\
\hline$A C A C A$ & Abcam & ab72046 & 1:1000 \\
\hline FABP3 & Abcam & ab231568 & $1: 1000$ \\
\hline DGAT1 & Abcam & ab181180 & 1:1000 \\
\hline SREBP1 & Abcam & ab3259 & $1: 1000$ \\
\hline alpha-S1-casein & Santa Curz & sc365929 & $1: 100$ \\
\hline beta-casein & Santa Curz & sc166520 & $1: 100$ \\
\hline WAP & Santa Curz & sc398276 & $1: 100$ \\
\hline Phospho-AMPK & CST & 2535 & 1:1000 \\
\hline AMPK & CST & 2532 & $1: 1000$ \\
\hline Phospho-mTOR & CST & 5536 & $1: 1000$ \\
\hline mTOR & CST & 2983 & 1:1000 \\
\hline Phospho-S6K1 & CST & 9234 & $1: 1000$ \\
\hline S6K1 & CST & 9202 & 1:1000 \\
\hline Phospho-4EBP1 & CST & 9451 & 1:1000 \\
\hline 4EBP1 & Abcam & ab32024 & $1: 1000$ \\
\hline Phospho-JAK2 & CST & 3776 & $1: 1000$ \\
\hline JAK2 & CST & 3230 & $1: 1000$ \\
\hline Phospho-STAT5 & CST & 4322 & 1:1000 \\
\hline STAT5 & CST & 94205 & $1: 1000$ \\
\hline Phospho-p38 & CST & 4511 & $1: 1000$ \\
\hline p38 & CST & 8690 & 1:1000 \\
\hline SirT1 & CST & 8469 & $1: 1000$ \\
\hline$\beta-\operatorname{TrcP}$ & CST & 4394 & $1: 1000$ \\
\hline $\operatorname{Pr} I R$ & Abcam & ab170935 & $1: 1000$ \\
\hline PGC-1a & Santa Curz & sc518025 & $1: 100$ \\
\hline Acetylated-lysine & CST & 9441 & $1: 1000$ \\
\hline Anti-ubiquitin & Abcam & ab140601 & $1: 2000$ \\
\hline $\lg G$ & Santa Curz & sc2025 & $1: 100$ \\
\hline$\beta$-actin & Abcam & ab8226 & $1: 2000$ \\
\hline Goat anti-mouse IgG & ZENBIO & 511103 & $1: 5000$ \\
\hline Goat anti-rabbit lgG & ZENBIO & 511203 & $1: 5000$ \\
\hline Goat anti-mouse IgG & Jackson & 115545003 & $1: 500$ \\
\hline
\end{tabular}

triacylglyceride. The determination of triacylglyceride concentration was achieved by detecting the OD value of the sample at a wavelength of $510 \mathrm{~nm}$ as the instructions suggested.

\section{Western-blotting}

As with the previous steps for determining the triglyceride concentration, the HC11 cells were first fully lysed by RIPA ( $160 \mu \mathrm{L}$ per well for 6 -well plates). After the cell lysate were denatured by high temperature by using a PCR instrument, they were mixed with the 40 $\mu \mathrm{L}$ loading buffer per well and used as the sample for 
Table 3 Primer sequences for real-time PCR

\begin{tabular}{|c|c|c|c|}
\hline Genes & Forward primers & Reverse primers & Size, bp \\
\hline FASN & AGCACTGCCTTCGGTTCAGTC & AAGAGCTGTGGAGGCCACTTG & 94 \\
\hline ACACA & GAAGTCAGAGCCACGGCACA & GGCAATCTCAGTTCAAGCCAGTC & 119 \\
\hline FABP3 & ACCTGGAAGCTAGTGGACAG & TGATGGTAGTAGGCTTGGTCAT & 106 \\
\hline DGAT1 & CAGCTGTGGCCTTACTGGTTGA & CGGCACCACAGGTTGACATC & 118 \\
\hline SREBP1 & AGAAGCTCAAGCAGGAGAACCTGA & ACTTCGGGTTTCATGCCCTCCATA & 127 \\
\hline AMPK & AACCTGAGAACGTCCTGCTTGATG & TGACTTCTGGTGCGGCATAATTGG & 132 \\
\hline CSNS1 & AATTCTTCCAGCTTGGTGCCTCTC & CAATGCCTTCAGGGGTGTCGTAG & 105 \\
\hline CSN2 & AGGAACAGCAGCAAACAGAGGATG & GGCTGAAGAGGCGGCAGAAAG & 136 \\
\hline WAP & ACAGAGTGTATCATCTGCCAAA & ACCAATGTTGACAGGAGTTTTG & 102 \\
\hline PCG-1a & CAGAGAGTATGAGAAGCGAGAG & AGCATCACAGGTATAACGGTAG & 232 \\
\hline PrlR & CCTGAAATCCACAAATGTCGTT & CATATGGAAGTGTACTGCTTGC & 197 \\
\hline PIP & CATCAACAGCACAGGAAAATCA & AGGATGATCATTACAGAGGCAG & 158 \\
\hline BCAT & TTTGCTGGAGAAAGAGGATCAG & GCTTCTCTTTTAAGACAGTGGC & 91 \\
\hline GPT & CTTCAAGCAGTTTCAAGCAGAG & TTGAGGGAAGGAATACATAGCG & 139 \\
\hline GOT & ACAAGAACACACCAATCTACGT & ATAGGGCCGAATGTCCTTAAAA & 92 \\
\hline ASCT2 & TCCTTTCTAGATCTCGTGAGGA & CTGGACCATGGTTGAATTGATC & 150 \\
\hline ASCT1 & GCAGGACAGATTTTTCACCATTC & CAAGATGATGGCAATTGTGAGG & 99 \\
\hline$x \subset T$ & CTATTTTACCACCATCAGTGCG & ATCGGGACTGCTAATGAGAATT & 102 \\
\hline CAT2 & CATCGGAATAGTGACGTCCTTA & AAGGCATCATAAGCGTTAAAGC & 80 \\
\hline CAT1 & CTGTGTTTTGGTCTTACGGTAC & AAAAAGCCTGTCTGTGATTCAC & 132 \\
\hline $4 \mathrm{~F} 2 \mathrm{hc}$ & AGGGACTCCTGTTTTTTAGCTAC & GTGAAAGATGCTGGACTCATTC & 109 \\
\hline LAT2 & TGGATCCTTACAAGAACCTTCC & CATTGCAGTGACGTATGCAATA & 98 \\
\hline ACTIN & CCACCATGTACCCAGGCATT & CGGACTCATCGTACTCCTGC & 190 \\
\hline
\end{tabular}

subsequent experiments. Under the action of electrophoresis, the proteins in the sample were separated by $10 \%$ or $12 \%$ SDS-PAGE gels. Then, the protein molecules were transferred onto the PVDF membrane in the tris-glycine system. Immediately afterwards, the PVDF membranes were rinsed with TBST 3 times and blocked with $6 \%$ skimmed milk for two hours at room temperature. The PVDF membranes were then rinsed 3 times with TBST and incubated under gentle shaking overnight at $4^{\circ} \mathrm{C}$ with the primary antibodies. After overnight incubation, the PVDF membranes were rinsed 3 times with TBST and incubated under gentle shaking at room temperature for $1 \mathrm{~h}$ with the secondary antibodies. The chemiluminescent signal was detected using super ECL reagents (P1020), and signals obtained were quantified by ImageJ Software (Image J 1.52a). All antibodies used in this experiment (including subsequent immunofluorescence and immunoprecipitation experiments) are shown in Table 2.

\section{Immunofluorescence staining}

As shown in previous studies, immunofluorescence staining was performed to determine the location and yield of the target protein. We use 96-well plates to culture and process cells for immunofluorescence. The cells were washed, fixed with $4 \%$ paraformaldehyde, treated with tiriton X-100, and blocked with 5\% BSA, and then incubated with the primary antibodies and the secondary antibodies in turn. After being stained by DAPI, the cells were observed and imaged under a fluorescence microscope.

\section{Immunoprecipitation}

In order to detect the degree of acetylation or ubiquitination of a single protein, we introduced immunoprecipitation to separate the target protein from other proteins, and then used the corresponding antibodies to bind to the target protein. The main steps are as follows: (1) fully lyse the cells cultured in the culture dishes with CHAPS 

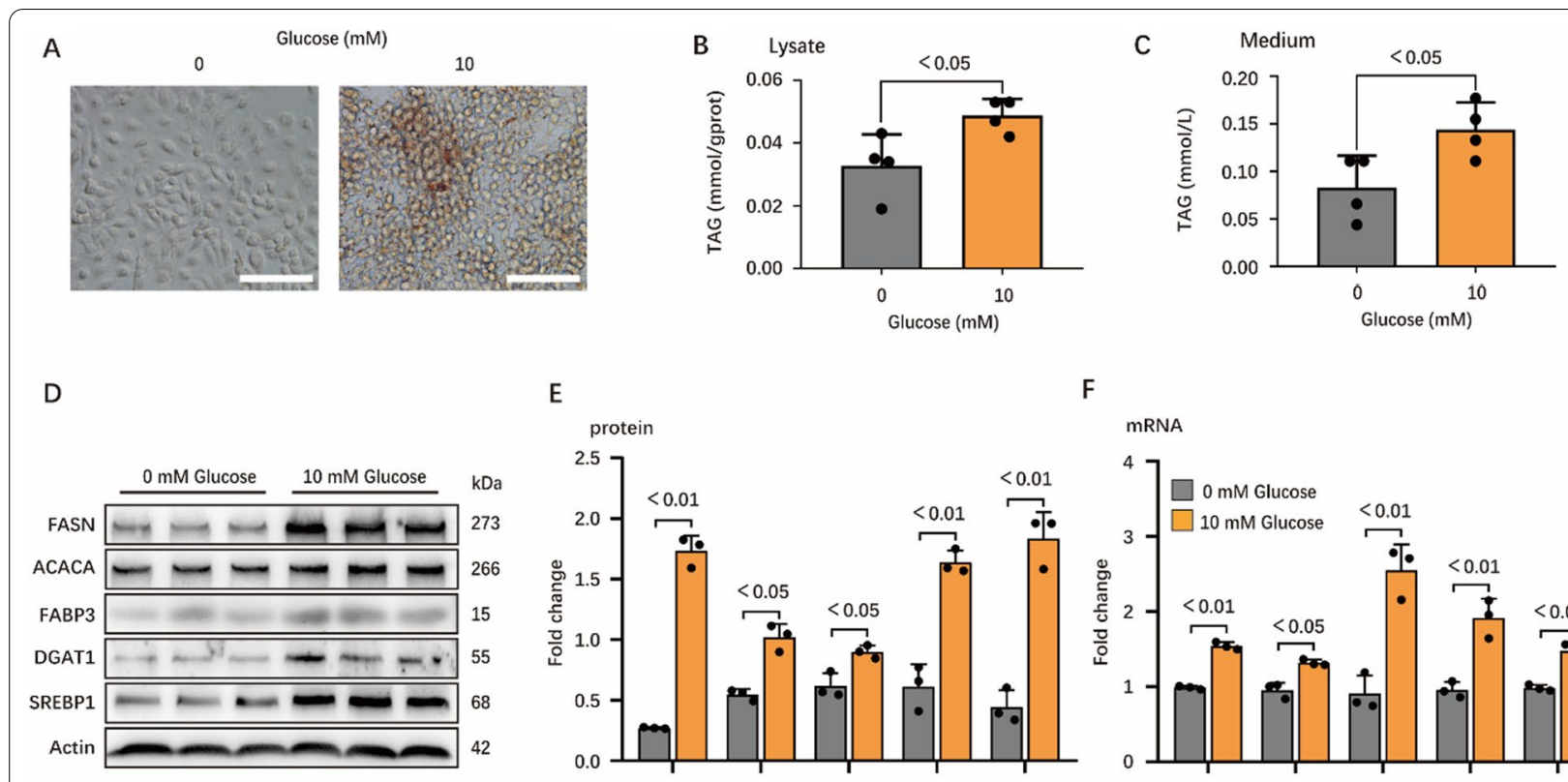

E

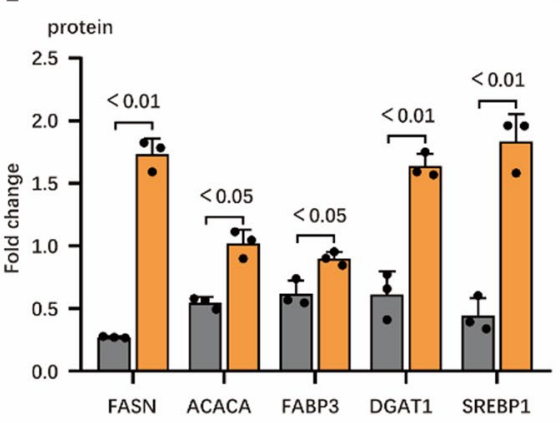

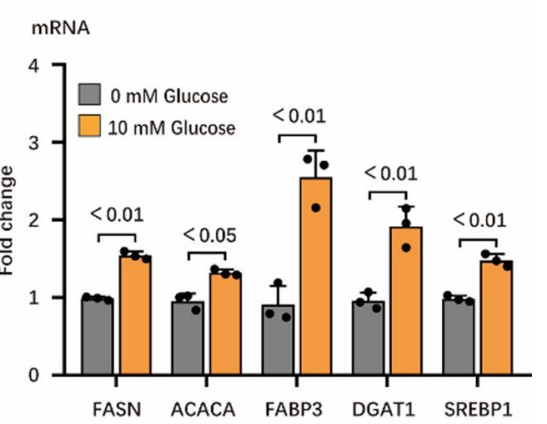

G

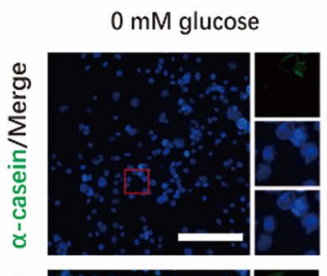

$10 \mathrm{mM}$ glucose

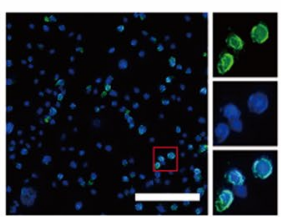

$\mathrm{H}$
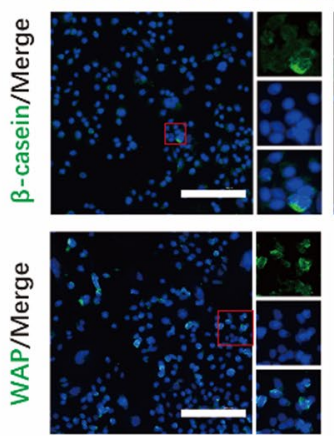
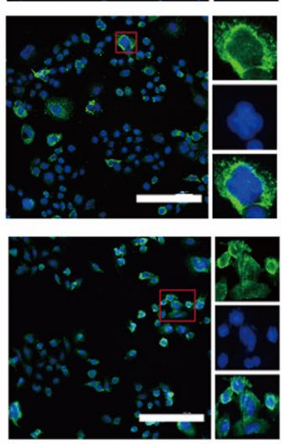
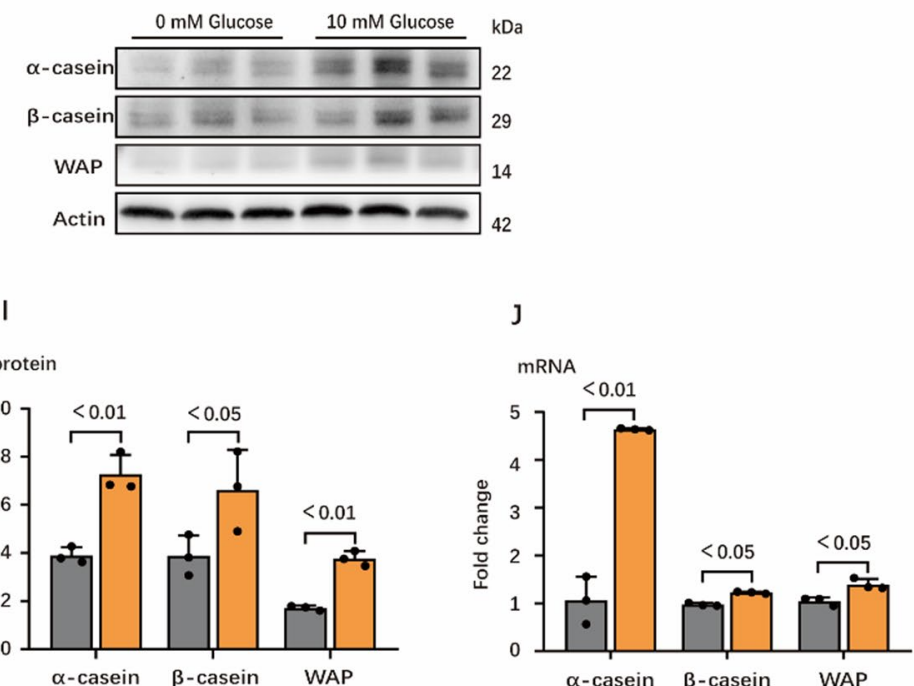

Fig. 1 Energy stress suppresses synthesis of milk fat and protein in HC11. A Oil red O staining images of HC11 under 0 mM glucose (left) and $10 \mathrm{mM}$ glucose (right). Scale bars are $100 \mu \mathrm{m}$. B and C TAG concentration in cell (B) and medium (C), $n=4$. D-F Western blots of HC11 lysates. In (D), bands were incubated with target proteins including FASN, ACACA, FABP3, DGAT1, SREBP1 and Actin antibodies, $n=3$. Protein expressions of target proteins are shown in (E), $n=3$. $\mathbf{F}$ Relative mRNA expression of target proteins, $n=3$. G Confocal microscopy of HC11 immunostained for a-casein (green), $\beta$-casein (green), WAP (green) and DAPI (blue). Scale bars, $100 \mu \mathrm{m}$. The small red boxes in the figure are typical areas selected, and the three small images on the right are the enlarged images of the target protein, nucleus and merge images in selected areas, respectively. $\mathbf{H}-\mathbf{J}$ Western blots and real time PCR of HC11 lysates of genes critical for protein synthesis. In $(\mathbf{H})$, bands were incubated with target proteins including a-casein, $\beta$-casein, WAP and Actin antibodies, $n=3$. Protein expressions of target proteins are shown in $(\mathbf{I}), n=3$. $\mathbf{J}$ Relative mRNA expressions of target proteins, $\mathrm{n}=3$. In this figure, cells for oil red O staining, TAG determination, immunofluorescence staining and WB were collected after $24 \mathrm{~h}$ incubation with $0 \mathrm{mM}$ and $10 \mathrm{mM}$ glucose mediums and cells for real-time PCR are $12 \mathrm{~h}$. All data with error bars are averages $\pm S E M$. In histograms, the numbers above the column are the $p$-values marked as a range if significantly different $(P<0.05)$ and each small black dot represents a test value 
lysis buffer (TIANDZ, China), and centrifuge the lysate to collect the supernatant; (2) take a small part of the supernatant and save it for later use, and add IgG and the target protein antibody to the rest and incubate at $4{ }^{\circ} \mathrm{C}$ for $2 \mathrm{~h}$; (3) add the A/G beads (washed and blocked in advance) (Santa cruz, sc2003) to the solution in the previous step, and incubate it overnight at $4{ }^{\circ} \mathrm{C}$; (4) discard the supernatant and add chaps buffer, then bath at $100{ }^{\circ} \mathrm{C}$ for $5 \mathrm{~min}$; after centrifugation, the supernatant and loading buffer are mixed. The subsequent operations are basically the same as western-blotting.

\section{Real-time PCR}

The cells were harvested after $12 \mathrm{~h}$ incubation for real-time PCR. Total RNA was isolated from cells by using EZ-press RNA Purification Kit (EZ-Bio, Shanghai) according to the protocol. After being tested the purity and integrity via agarose gel electrophoresis, the RNA was then reverse transcribed into cDNA by Color Reverse Transcription Kit (EZ-Bio, Shanghai) including gDNA removers and colored mix. The diluted cDNA was thoroughly mixed with Color SYBR Green qPCR Mix (EZ-Bio, Shanghai) and the primers of the target gene as well as double distilled water to form a $20 \mu \mathrm{L}$ system for qPCR. The thermal cycling conditions of qPCR reactions were as follows: $95{ }^{\circ} \mathrm{C}$ for $1 \mathrm{~min}$ followed by 40 cycles of denaturation at $95{ }^{\circ} \mathrm{C}$ for $15 \mathrm{~s}$, annealing at $59{ }^{\circ} \mathrm{C}$ for $15 \mathrm{~s}$, and extension at $72{ }^{\circ} \mathrm{C}$ for $40 \mathrm{~s}$. Primer suquences we used for real-time PCR were listed in Table 3.

\section{Statistical analysis}

Data of western-blotting, real-time PCR and TAG concentration were analyzed by one-way analysis of variance using IBM SPSS Statistics 20.0. The graphs were performed and analyzed with GraphPad Prism software 8.0. All data were demonstrated as (mean + SEM, n). $P<0.05$ was considered as statistically significant and $P<0.01$ was considered as highly statistically significant.

\section{Results}

Glucose starvation inhibits milk fat and protein synthesis As a major energy source for epithelial cells of the mammary gland, glucose starvation increases cellular AMP/ ATP ratio and triggers energy stress. To understand the effects of energy stress on milk synthesis, we first studied the effects of glucose starvation on milk protein and fat synthesis in mouse mammary epithelial cell line HC11. As expected, glucose starvation dramatically inhibited the milk fat synthesis (Fig. 1A-C). Correspondingly, protein (Fig. 1D, E) and gene (Fig. 1F) levels of critical enzymes (FASN, ACACA, FABP3 and DGAT1) participating in milk fat de novo synthesis and the regulatory factor (SREBP1) were also down-regulated under glucose starvation. We further detected the effects of glucose starvation on milk protein synthesis. Similarly, we observed positive reactions to $\alpha$-casein, $\beta$-casein and WAP in the cytoplasm of HC11 cells treated with $0 \mathrm{mM}$ glucose, while they were greatly inhibited compared with cells treated with $10 \mathrm{mM}$ glucose (Fig. 1G). Milk protein synthesis was significantly inhibited during glucose deficiency, as is shown by the results from proteins (Fig. 1H, I) and genes expression (Fig. 1J) of milk protein $(\alpha$-casein, $\beta$-casein and WAP). In order to confirm the effects of glucose on epithelial cells of the mammary gland, glucose dose-dependent experiment was conducted on porcine mammary gland epithelial cells (pMECs). Similar to the results from HC11 cell line,

\footnotetext{
(See figure on next page.)

Fig. 2 AMPK activation attenuates synthesis of milk fat and protein in HC11. A Oil red O staining images of HC11. Scale bars are $100 \mu \mathrm{m}$. B and C TAG concentration in cells $(\mathbf{B})$ and medium $(\mathbf{C}), n=4$. D Heatmap analysis of up-regulated (red) or down-regulated genes (green) in $H C 11, n=3$. The $0 \mathrm{mM}$ glucose group and the Phe group were compared with the $10 \mathrm{mM}$ group respectively, ${ }^{*}$ means $P<0.05,{ }^{* *}$ means $P<0.01$ and ${ }^{* * *}$ means $P<0.001$. E-G Western blots and real time PCR of HC11 lysates for critical fat synthesis genes. $\mathbf{E}$ Representative western-blotting bands hybridized with target proteins including FASN, ACACA, FABP3, DGAT1, SREBP1 and Actin antibodies, $n=3$. (F) is the result of analyzing the WB bands and (G) represents data from real-time $P C R, n=3$. H Confocal microscopy of HC11 immunostained for a-casein (green), $\beta$-casein (green), WAP (green) and DAPI (blue). Scale bars, $100 \mu \mathrm{m}$. The small red boxes in the figure are typical areas selected, and the three small images on the right are the enlarged images of the target protein, nucleus and merge images in selected areas, respectively. I-K Western blots and real time PCR of HC11 lysates for critical protein synthesis genes. I Representative western-blotting bands hybridized with target proteins including a-casein, $\beta$-casein, WAP and Actin antibodies, $n=3$. J Result of analyzing the WB bands and (K) represents data from real-time $P C R, n=3$. In this figure, cells for oil red $O$ staining, TAG determination, lipidomics, immunofluorescence staining and WB were collected after $24 \mathrm{~h}$ incubation with $0 \mathrm{mM}$ glucose medium, $10 \mathrm{mM}$ glucose medium, (10 mM glucose + $1.5 \mathrm{mM}$ AICAR) medium and (10 mM glucose $+300 \mu \mathrm{M}$ Phe) medium, and cells for real-time PCR are $12 \mathrm{~h}$. All data with error bars are averages \pm SEM. In histograms, the numbers above the column are the $p$-values marked as a range if significantly different $(P<0.05)$ and each small black dot represents a test value
} 

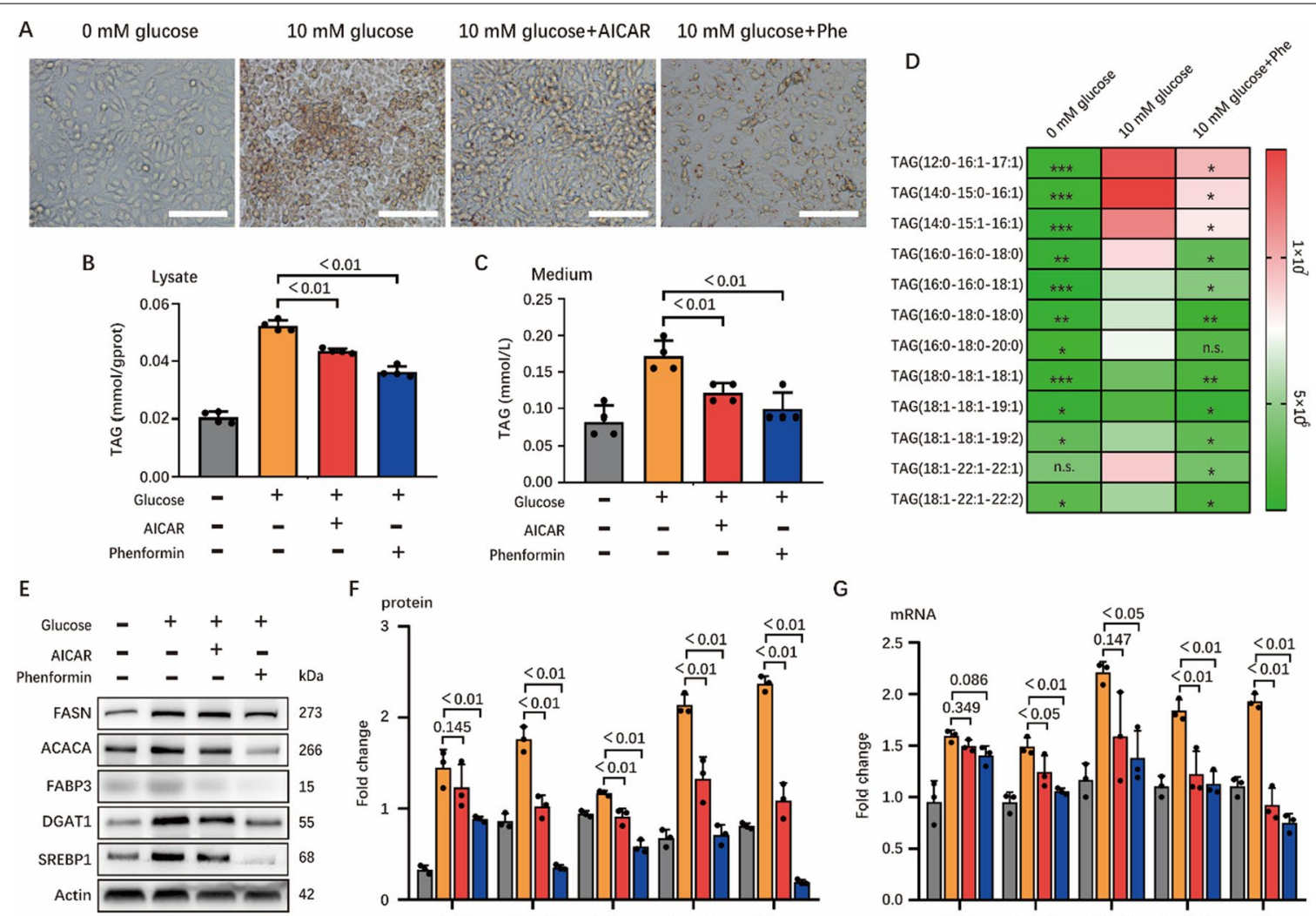

\section{G}
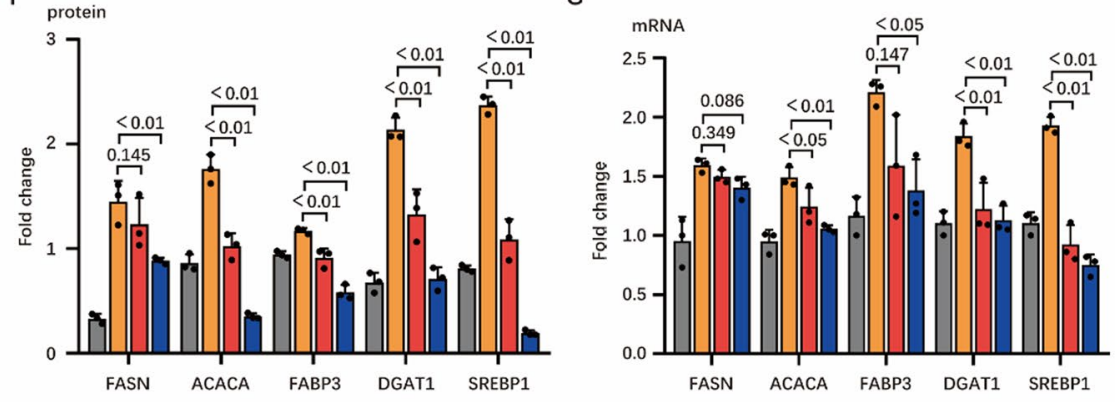

$\mathrm{H}$
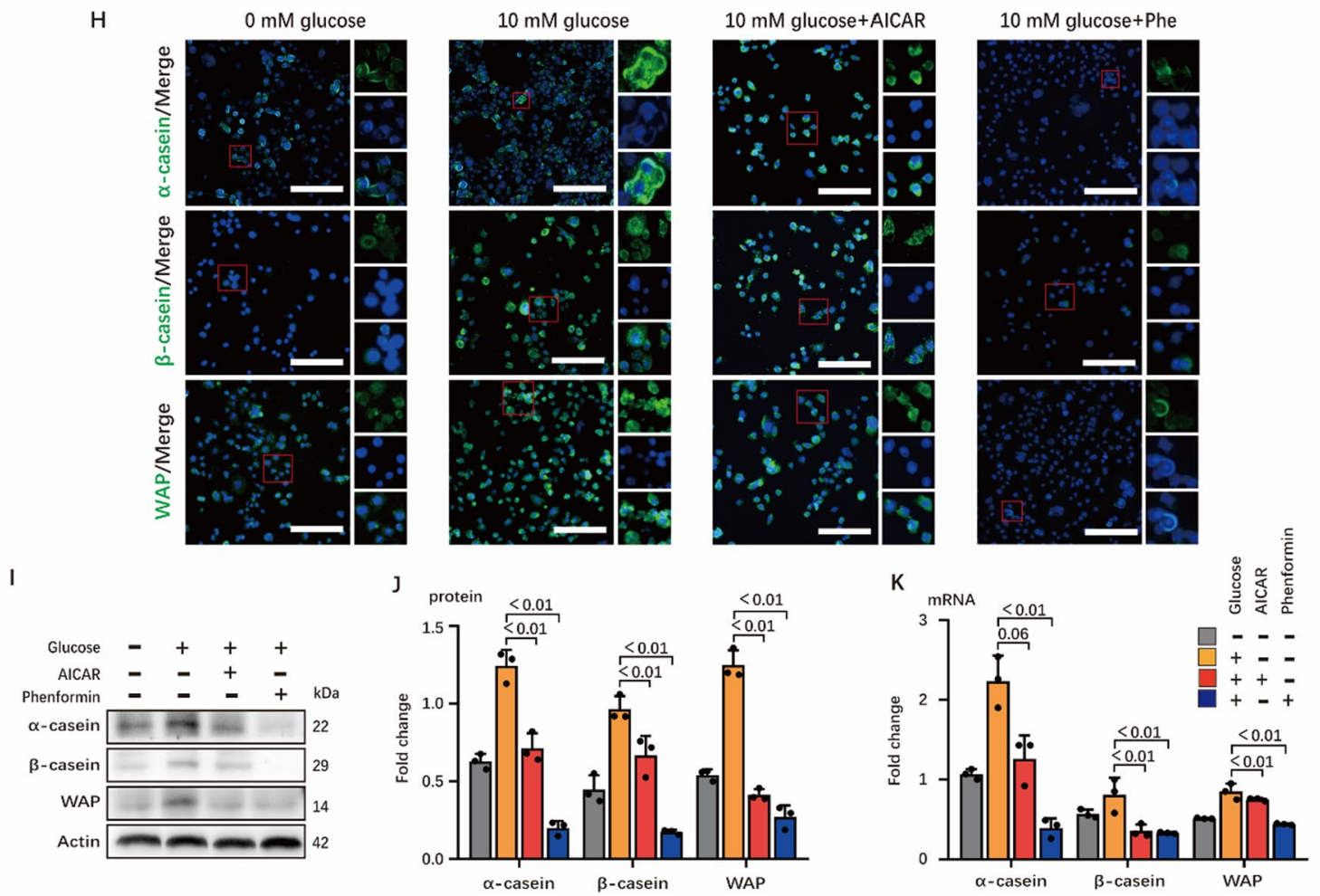

Fig. 2 (See legend on previous page.) 
treating pMECs with different concentration of glucose after glucose starvation dose-dependently increased the milk fat synthesis (Additional file 1: Fig. S1A) with the upregulation of fat de novo synthesis enzymes (Additional file 1: Fig. S1B-C). Collectively, energy stress may inhibit milk fat (also verified in pMECs) and protein synthesis in $\mathrm{HC} 11$.

\section{AMPK activation mimics the negative effects of glucose starvation on milk fat and protein synthesis}

AMPK is a crucial sensor to detect cellular energy status. Glucose starvation was shown to decrease the cellular ATP/ADP ratio (Additional file 1: Fig. S1D) and activated AMPK in HC11 cells (Additional file 1: Fig. S1E-F). To identify the potential role of AMPK on milk fat and protein synthesis, we used compounds 5-aminoimidazole-4-carboxamide ribonucleotide (AICAR; an AMP analogue) and phenformin to activate AMPK to mimic the effects of glucose starvation. Strikingly, treatment with these compounds both highly inhibited (especially phenformin) milk fat synthesis (Fig. 2A-C). Furthermore, the type of triglyceride (LCFA saturation) that decreased during AMPK activation was detected (Fig. 2D). Significant decrease was observed in the levels of proteins (Fig. 2E, F) and genes (Fig. 2G) of enzymes related to milk fat synthesis. Similarly, synthesis of milk protein was also downregulated to varying degrees when AMPK was activated by AICAR and phenformin (Fig. $2 \mathrm{H}-\mathrm{K}$ ). In general, these results demonstrated that glucose starvation might inhibit milk fat and protein synthesis through AMPK signaling pathway.

\section{Energy stress inhibits milk fat and protein synthesis partially through AMPK}

To confirm the role of AMPK in energy stress-induced decrease of milk synthesis, we studied the role of AMPK inhibitor Compound $C$ in milk synthesis under glucose starvation. As fatty acid synthesis might require glucose as substrates, $2 \mathrm{mM}$ glucose was used to establish the slight glucose starvation model (Additional file 1: Fig. S2A), which could both activate AMPK and supply basic level of glucose as substrates. As expected, Compound $\mathrm{C}$ alleviated the negative effects of glucose starvation on milk fat synthesis (Fig. 3A-C) and enhanced the expression of proteins and genes of key enzymes (Fig. 3D-F). Immunofluorescent staining also showed that AMPK inhibition stimulated milk protein synthesis (Fig. 3G). Similar tendency was also observed in genes and proteins that related to milk protein synthesis (Fig. 3H-J). To further test whether the AMPK activity regulates milk fat and protein synthesis under energy stress, we knocked down AMPK using small interfering RNA (siRNA). The negative effects of AMPK on milk fat and protein synthesis were partially rescued when AMPK was knocked down (Fig. 3K, L). Intriguingly, milk fat and protein were significantly increased when $\mathrm{HC} 11$ was directly treated with compound $\mathrm{c}$ under severe energy deprivation $(0 \mathrm{mM}$ glucose) (Additional file 1: Fig. S2B-E), which indicates that other substrates might replace glucose for milk synthesis (as we will discuss below). Taken together, energy stress regulates milk fat and protein synthesis partially through AMPK signaling.

\footnotetext{
(See figure on next page.)
}

Fig. 3 Inhibition of AMPK promotes the synthesis of milk fat and protein in HC11. A Oil red O staining images of HC11. Scale bars are $100 \mu \mathrm{m}$. B and $\mathbf{C}$ TAG concentration in cell $(\mathbf{B})$ and medium $(\mathbf{C}), n=6$. D-F Western blots of HC11 lysates. In (D), bands were incubated with target proteins including FASN, ACACA, FABP3, DGAT1, SREBP1 and Actin antibodies, $n=3$. Protein expressions of target proteins are shown in $(\mathbf{E}), n=3$. $\mathbf{F}$ Relative mRNA expressions of target proteins, $\mathrm{n}=3$. G Confocal microscopy of HC11 immunostained for a-casein (green), $\beta$-casein (green), WAP (green) and DAPI (blue). Scale bars, $100 \mu \mathrm{m}$. The small red boxes in the figure are typical areas selected, and the three small images on the right are the enlarged images of the target protein, nucleus and merge images in selected areas, respectively. $\mathbf{H}-\mathbf{J}$ Western blots and real time PCR of HC11 lysates for critical protein synthesis genes. In (H), bands were incubated with target proteins including a-casein, $\beta$-casein, WAP and Actin antibodies, $n=3$. Protein expressions of target proteins are shown in $(\mathbf{I}), n=3$. (J) shows relative mRNA expressions of target proteins, $n=3$. $\mathbf{K}$ TAG concentration in cell (top) and medium (bottom), $n=6$. Cells are first transfected with siRNA and treated with the corresponding medium, the cell lysate and medium are then collected for detection. $\mathbf{L}$ Western blots of $\mathrm{HC} 11$ lysates for AMPK signaling pathway, critical milk protein and fat synthesis genes. In this figure, cells for oil red O staining, TAG determination, immunofluorescence staining and WB were collected after $24 \mathrm{~h}$ incubation with $0 \mathrm{mM}$ glucose medium, $2 \mathrm{mM}$ glucose medium and ( $2 \mathrm{mM}$ glucose $+50 \mu \mathrm{M}$ Compound C) medium and cells for real-time PCR are $12 \mathrm{~h}$. All datas with error bars are averages \pm SEM. In histograms, the numbers above the column are the $p$-values marked as a range if significantly different $(P<0.05)$ and each small black dot represents a test value 

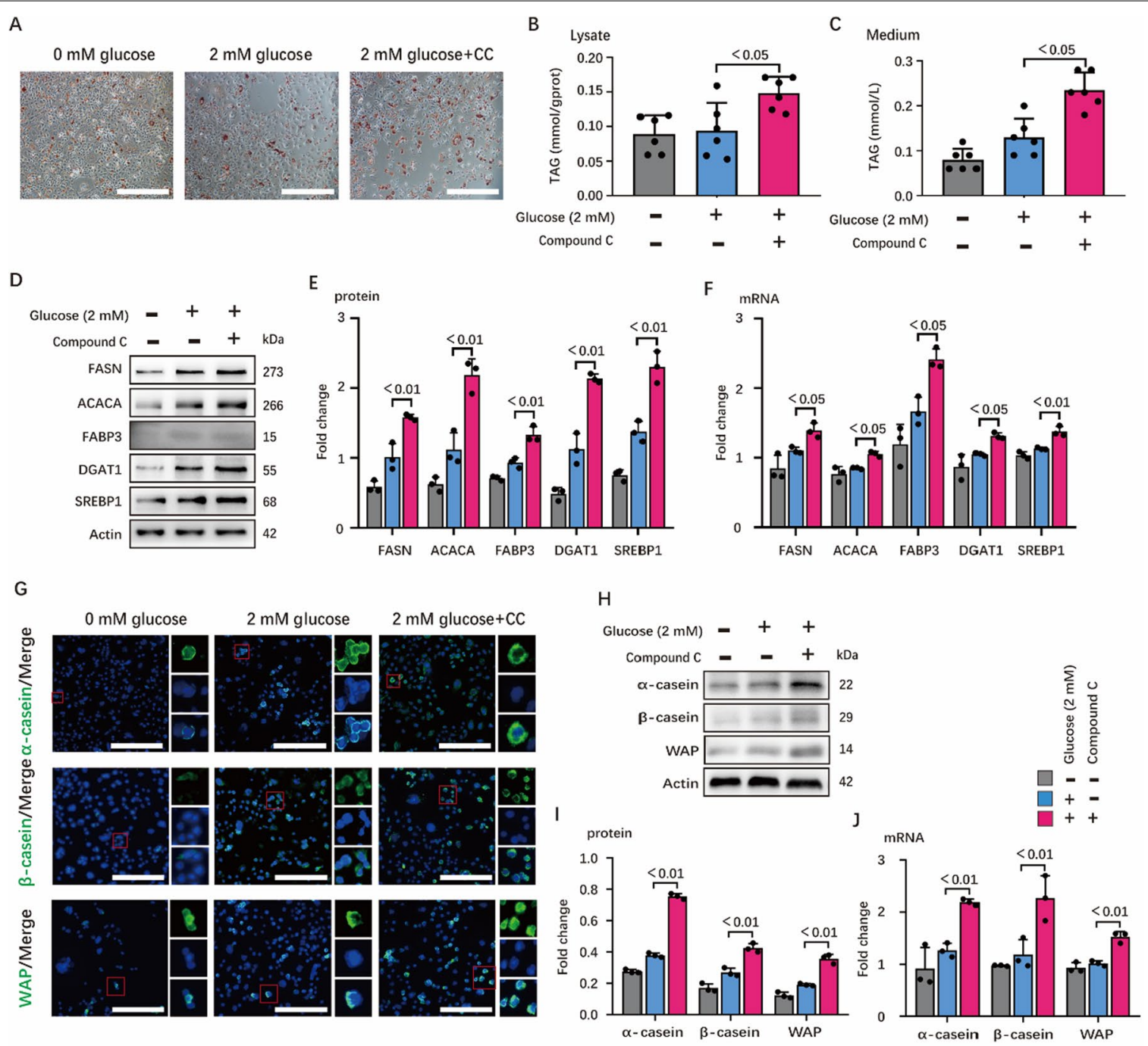

K

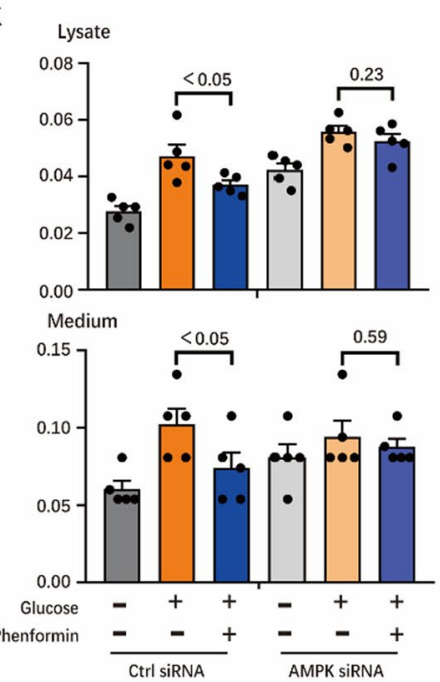

L

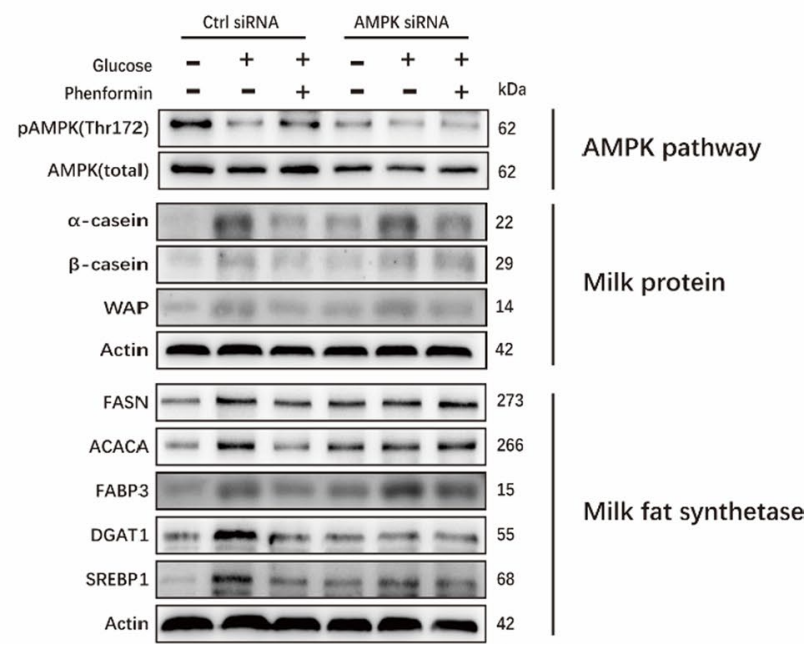

Fig. 3 (See legend on previous page.) 


\section{AMPK signaling regulates milk synthesis partially through mTORC1 pathway}

mTORC1 is a master regulator of cell growth and metabolism. Activation of mTORC1 further phosphorylates S6K1 and 4EBP1 and promotes protein synthesis, which might partially regulate milk fat and protein synthesis. In HC11 cell line, glucose starvation and/or AMPK agonists (AICAR and Phenformin) both inhibited mTORC1 signaling (phosphorylation of S6K1 and 4EBP1) (Additional file 1: Fig. S3A-B). Besides, glucose starvation also regulates the AMPK/mTORC1 pathway in PMEC (Additional file 1: Fig. S3C-D). In contrast, AMPK antagonist (Compound $C$ ) activated the mTORC1 signaling pathway (Additional file 1: Fig. S3EF). To further investigate the role of mTORC1 on milk fat and protein synthesis, we pretreated the HC11 cell line with rapamycin (an inhibitor of mTORC1) to inhibit mTORC1 pathway (Additional file 1: Fig. S4A-B) before glucose stimulation. Likewise, the positive effects of glucose on the expression of critical enzymes involved in milk fat (Additional file 1: Fig. S4C-H) and protein synthesis (Additional file 1: Fig. S4I-K) was inhibited. Thus, this evidence indicates the critical role of mTORC1 in milk synthesis.

\section{Energy stress might regulate milk synthesis through AMPK/PrIR pathway}

In order to discover novel mechanism of how energy stress regulates milk synthesis, RNA-seq was performed to compare the transcriptomes of $\mathrm{HC} 11$ cell line starved for glucose or treated with AMPK agonist with those under normal situation (Fig. 4A). GSEA analysis indicated that signaling pathways related to prolactin binding were significantly inhibited in group CON (glucose starvation) and group PHE (AMPK activation) (Fig. 4B). Intriguingly, the fold change of prolactin induced protein (PIP, considered as a downstream of PrlR signaling pathway) was prominent in the volcano map (Fig. 4C, D) and was ranked fourth and first in terms of up- and down-regulated genes in Fig. 4C, D, respectively (Fig. 4E, F). Therefore, we made a hypothesis that AMPK activation might decrease PrlR expression and inhibit its downstream signaling. Real-time PCR confirmed the decrease of PrIR and PIP in group CON and group PHE (Fig. 4G). Furthermore, the phosphorylation of JAK2 and STAT5 (downstream targets of PrlR signaling) were also significantly inhibited under glucose starvation or AMPK activation (Fig. 4H, I). We concluded that energy stress may regulate milk synthesis through PrlR pathway due to the significant change on AMPK/PrlR and its downstream pathways under AMPK activation.

Intriguingly, RNA-seq and GSEA analysis found that genes (4F2hc, xCT, CAT1, ASCT1, ASCT2) involved in amino acid transportation were up-regulated under glucose starvation and stimulation of phenformin (Additional file 1: Fig. S5A-B). These RNA-seq data were then confirmed by RT-PCR (Additional file 1: Fig. S5C). Even though amino acids were largely transported into cells, milk protein synthesis was still inhibited under glucose starvation and stimulation of phenformin, which was shown by our previous results. These evidences indicated that amino acids might not be used for milk synthesis, but stead metabolized for energy supply. Amino acid transaminase catalyzes the transfer of the amino group (-NH2), which converts amino acids into $\alpha$-keto acid for further metabolism. RNA-seq data and RT-PCR data further confirmed that multiple amino acid transaminases (BCAT2, GPT2, GOT1) were up-regulated with under glucose starvation (Additional file 1: Fig. S5D-E), which indicates that these amino acids could be used as energy supply.

\footnotetext{
(See figure on next page.)

Fig. 4 Activated AMPK induces the downstream PrIR/JAK2/STAT5/PIP pathway. A PCA of RNA-seq, $n=3$. B GSEA showing enrichment of prolactin receptor binding in $\mathrm{HC} 11$ differentially expressed genes. The graph (left) shows the result of the control group-vs-glucose group and another graph (right) shows glucose group-vs-PHE group. $\mathbf{C}$ and $\mathbf{D}$ Volcano plots based on the significantly different genes in each comparison group. $\mathbf{C}$ Volcano plot of the control group-vs-glucose group and $\mathbf{D}$ Glucose group-vs-PHE group. The dots that the arrows point to are PIP. $\mathbf{E}$ and $\mathbf{F}$ (E) are top 10 significantly up-regulated 10 genes in the con-vs-glu comparison, and (F) are top 10 significantly down-regulated in the glu-vs-PHE comparison. $\mathbf{G}$ Relative mRNA expressions of PrIP and PIP, $n=3$. $\mathbf{H}$ and I Western blots of HC1 1 lysates for PrIR/JAK2/STAT5 pathway. In (H), bands were incubated with target proteins and Actin antibodies, $n=3$. Protein expressions of target proteins are shown in $(\mathbf{I})$, $n=3$. In this figure, cells for WB were collected after $24 \mathrm{~h}$ incubation with $0 \mathrm{mM}$ glucose medium, $10 \mathrm{mM}$ glucose medium and (10 mM glucose $+300 \mu \mathrm{M}$ Phe) medium and cells for real-time PCR and RNA-seq are $12 \mathrm{~h}$. All data with error bars are averages \pm SEM. In histograms, the numbers above the column are the $\mathrm{p}$-values marked as a range if significantly different $(P<0.05)$ and each small black dot represents a test value
} 


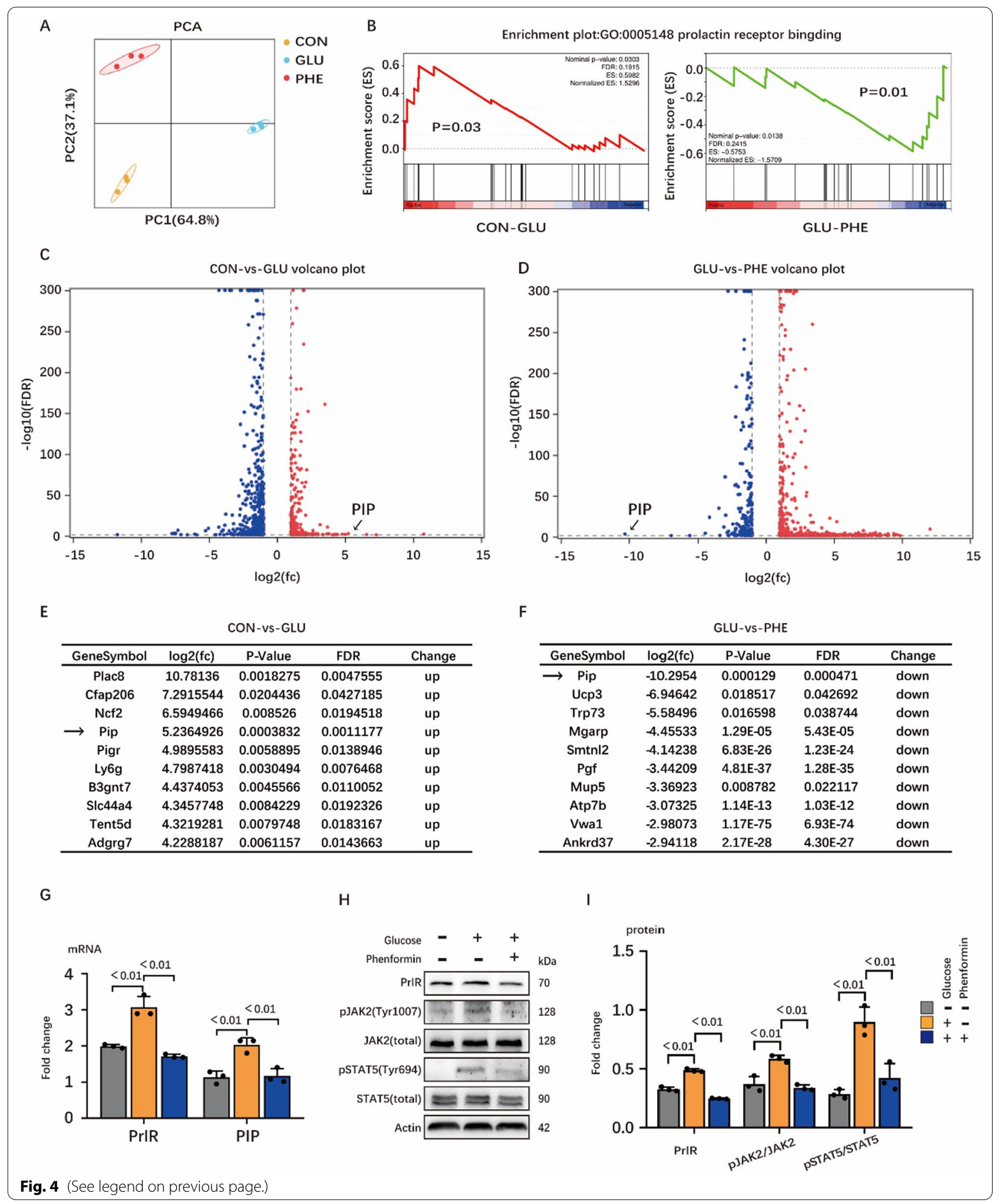


AMPK activation plays a role in the ubiquitination-induced degradation of PrIR by up-regulating the activity of $\beta-\operatorname{TrCP}$ In order to confirm whether the PrlR signaling is involved in AMPK-regulated milk fat and protein synthesis, we knocked down PrlR using siRNA. After PrlR knockdown, AMPK activation still inhibited milk fat synthesis (Fig. 5A, B). Nevertheless, the synthesis of milk protein was significantly suppressed after PrlR knockdown as is shown by immunofluorescence images (Fig. 5C). Besides, we also observed similar trends at the protein level (Fig. 5D, E). Thus, PrlR seems to promote the synthesis of milk protein but not milk fat.

PrlR is a transmembrane protein, its degradation could be regulated by a variety of physiological processes (such as ubiquitination) and multiple organelles (such as proteasomes and lysosomes). Thus, we then studied the degradation mechanism of PrlR. The results showed that PrlR seems to be taken up more through endocytosis and finally be degraded by lysosomes (Fig. 6A-C). F-box protein $\beta$-transducin repeat-containing protein $(\beta-\operatorname{TrCP})$ is a component of the ubiquitin ligase complex that triggers ubiquitindependent degradation of multiple proteins. We found that $\beta$-TrCP was significantly up-regulated under AMPK activation, which is accompanied with the degradation of PrlR (Fig. 6D, E). Importantly, when the $\beta-\operatorname{TrCP}$ was knocked down by siRNA, its induction of PrlR degradation was reduced (Fig. 6D-F). Consistent with this, the expression level of milk protein also decreased with the knockdown of $\beta$-TrCP (Fig. 6D-G). In order to confirm that the degradation of PrlR may be due to $\beta$-TrCP-induced ubiquitination, we used MA (lysosomal inhibitor) to block the degradation process, and used immunoprecipitation to observe the ubiquitination of PrlR. We found that AMPK activation can significantly promote the ubiquitination of
PrlR (Fig. 6H). In subsequent experiments, we found that knockdown of $\beta$-TrCP can weaken the ubiquitination of PrlR (Fig. 6I). In summary, AMPK activation can promote the degradation of PrlR under lysosome endocytosis, specifically by up-regulating the activity of $\beta-\operatorname{TrCP}$ to regulate ubiquitination-induced degradation of PrlR.

\section{AMPK activation up-regulates the expression of PGC-1a and enhances the $\beta$-oxidation of fatty acids by inhibiting PGC-1 $\alpha$ acetylation}

In order to identified how AMPK regulates milk fat level, we considered to study the process of fatty acids synthesis and fatty acid $\beta$-oxidation. Previously, ACC (critical enzyme involved in fatty acid synthesis) and PGC- $1 \alpha$ (critical enzyme involved in fatty acid $\beta$-oxidation) were identified as downstream targets of AMPK and found to play significant roles in fat metabolism in hepatocyte [12] and adipocyte [13]. Since a number of evidences have already indicated that ACC can affect fat production in mammary gland. Here, we would illustrate the impact of AMPK on milk fat synthesis from the perspective of fatty acid oxidation, thus, we took PGC- $1 \alpha$ as the entry point. Subsequent tests further proved that the negative effect of AMPK on milk fat synthesis was partially rescued when PGC-1 $\alpha$ was knocked down (Fig. 7A-C). These evidence clearly indicated that AMPK might regulate milk fat synthesis mainly through PGC- $1 \alpha$ in mammary epithelial cells.

Since previous studies have found that AMPK regulates PGC-1 $\alpha$ through p38 MAPK [14] or Sirt1 [15] in cancer cells and skeletal muscle, we further investigated the relationship between AMPK and PGC-1 $\alpha$ in HC11. We found that AMPK activation inhibits the phosphorylation of $\mathrm{p} 38$ pathway. When $\mathrm{p} 38$ was inhibited, the expression of PGC- $1 \alpha$ was increased independent of the activation

\footnotetext{
(See figure on next page.)

Fig. 5 Knock-down of PrIR lowers synthesis of milk protein but little affects milk fat. $\mathbf{A}$ and $\mathbf{B}$ TAG concentration in cell $(\mathbf{A})$ and medium (B), $\mathrm{n}=6$. C Confocal microscopy of HC11 immunostained for a-casein (green), $\beta$-casein (green), WAP (green) and DAPI (blue). Scale bars, $100 \mu \mathrm{m}$. The small red boxes in the figure are typical areas selected, and the three small images on the right are the enlarged images of the target protein, nucleus and merge images in selected areas, respectively. $\mathbf{D}$ and $\mathbf{E}$ Western blots of HC11 lysates for critical milk protein synthesis genes. $\mathbf{D}$ Representative western-blotting bands hybridized with target proteins including a-casein, $\beta$-casein, WAP and Actin antibodies, $n=3$. E Result of analyzing the WB bands. In this figure, cells (transfected by siRNA in advance) for TAG determination, immunofluorescence staining and WB were collected after $24 \mathrm{~h}$ incubation with $10 \mathrm{mM}$ glucose medium and (10 mM glucose + $300 \mu \mathrm{M}$ Phe) medium. All datas with error bars are averages \pm SEM. In histograms, the numbers above the column are the $p$-values marked as a range if significantly different $(P<0.05)$ and each small black dot represents a test value
} 


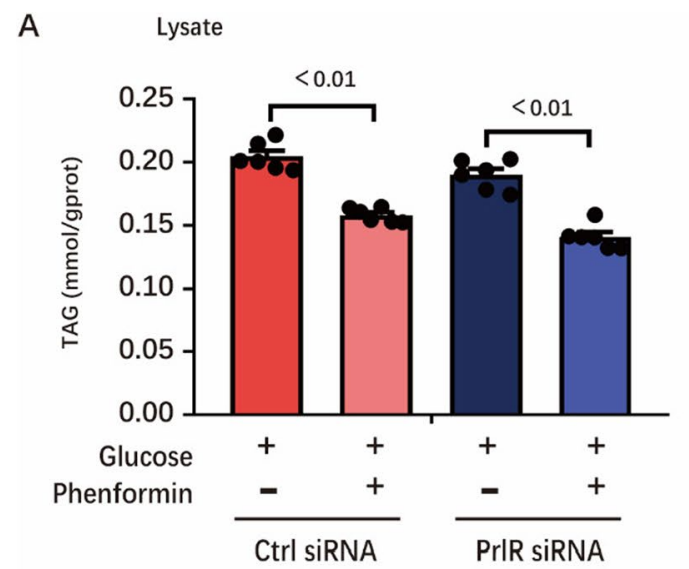

C
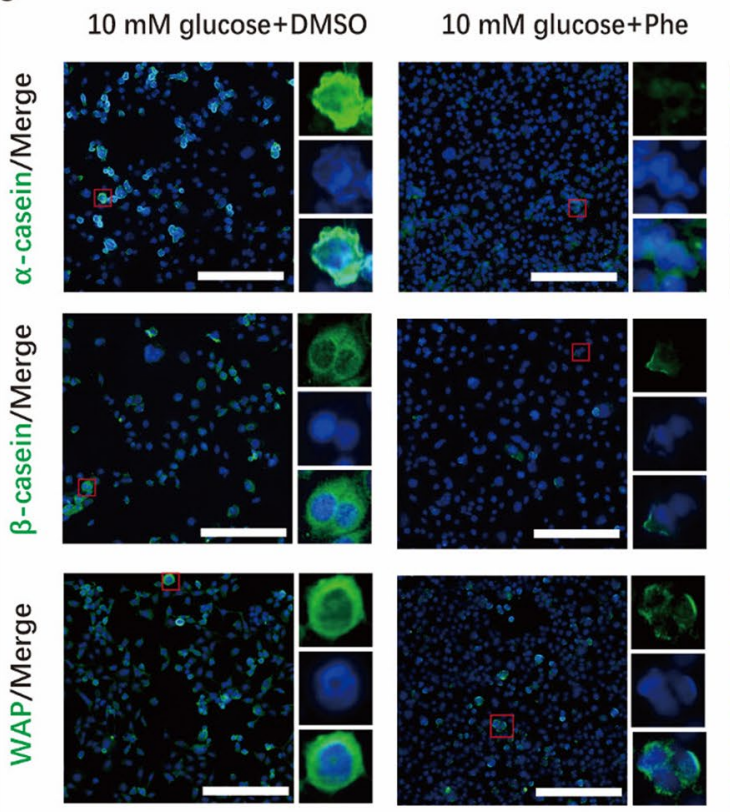

Ctrl siRNA

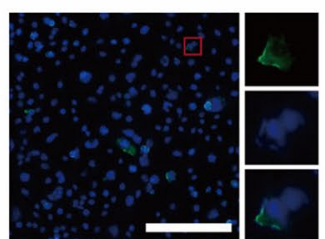

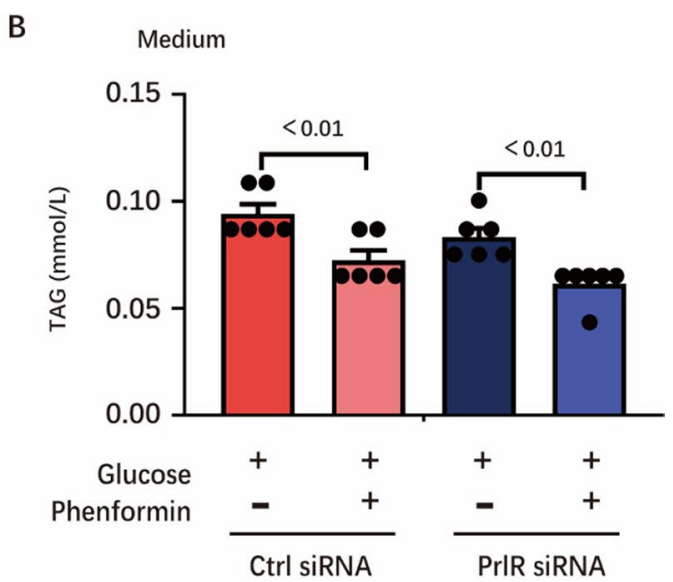

$10 \mathrm{mM}$ glucose+DMSO

$10 \mathrm{mM}$ glucose $+\mathrm{Phe}$
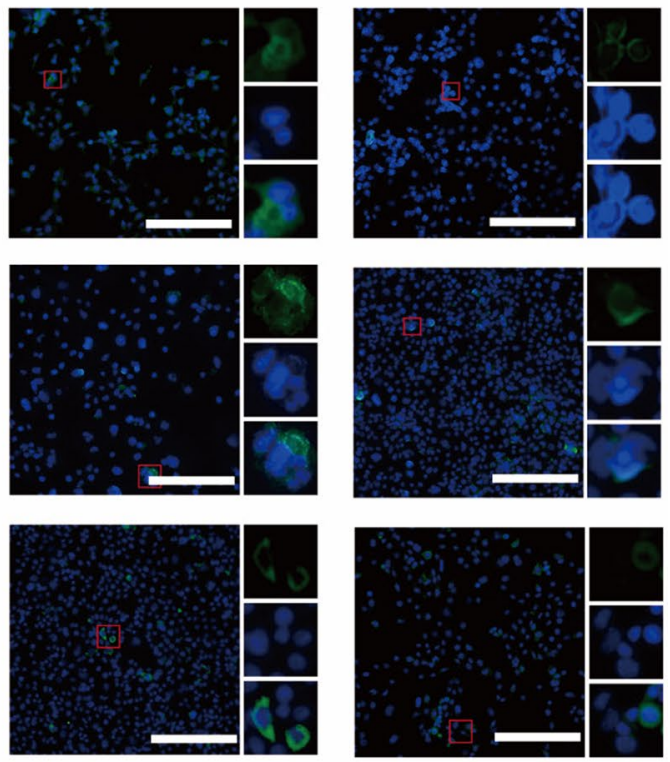

PRLr siRNA

D

E protein
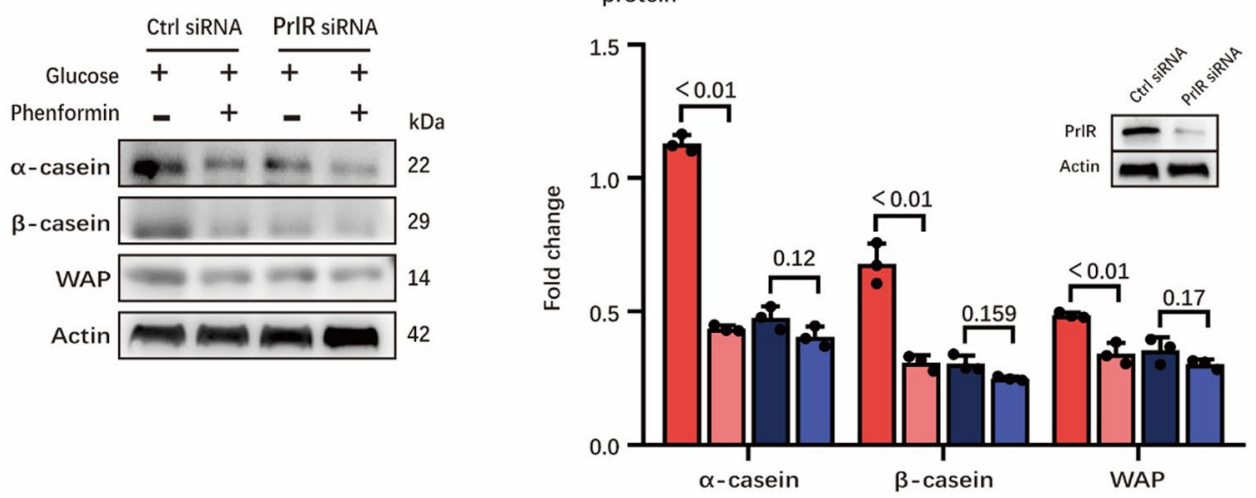

Fig. 5 (See legend on previous page.) 
of AMPK (Fig. 7D, E). Regarding Sirt1, although AMPK activation promotes Sirt1 expression, Sirt1 knockdown has no effect on PGC expression induced by AMPK (Fig. 7F, G). In order to explore its mechanism, we used immunoprecipitation to observe the relationship between AMPK and the acetylation of PGC- $1 \alpha$. We found that glucose starvation or AMPK activation decreased the acetylation level of PGC-1 $\alpha$ (Fig. $7 \mathrm{H}$ ). Collectively, AMPK might regulate milk fat synthesis partially by up-regulating the activity of PGC-1 $\alpha$ and inhibiting its acetylation.

\section{Discussion}

The intimate relationship between milk synthesis and AMPK signaling has been identified for a long time [16], whereas the underlying mechanism is not well characterized. Here, we identified two novel target proteins (PrlR and PGC-1 $\alpha$ ) of AMPK signaling that are involved in the regulation of milk synthesis. Mechanistically, AMPK triggers the ubiquitination and degradation of PrlR through $\beta$-TrCP, which then attenuates the PrlR-JAK2-STAT5 pathway involved in milk protein synthesis. At the same time, AMPK decreases the acetylation process of PGC- $1 \alpha$ and inhibits milk fat accumulation.

PrlR signaling regulates the growth and maturation of the mammary gland, which is also critical for the maintenance of lactation [17]. PrlR deficiency significantly inhibits milk protein synthesis. In this study, RNA-seq data revealed that the gene expression of PrlR was downregulated when AMPK was activated, which indicates AMPK might regulate milk protein synthesis through PrlR. Ubiquitination is one of the crucial mechanism to induce the degradation of hormone receptors [18]. Studies have shown that AMPK could control the uptake of long-chain fatty acids (LCFA) by regulating the expression of the membrane receptor CD36 through Parkinmediated polyubiquitination in intestinal epithelial cells [19]. Furthermore, the activation of AMPK triggers the interaction between $\beta$-TrCP and Glioma-associated oncogenes (GLI1), which induces $\beta$-TrCP-mediated GLI1-ubiquitination and degradation in human brain cancer cells [20]. Our results first revealed that PrlR was mainly degraded by lysosome through endocytosis process under the influence of AMPK activation. In the above process, AMPK activation up-regulated the activity of $\beta$-TrCP, which induced the ubiquitination degradation of PrlR.

PGC- $1 \alpha$ is considered as a transcriptional coactivator of PPAR $\gamma$ [21], which regulates fatty acid $\beta$-oxidation in the liver [22] and skeletal muscle [23]. To date, the role of PGC- $1 \alpha$ in mammary gland is still unclear. In this study, we found AMPK regulates milk fat production not only through the process of milk fat synthesis, but also the process of $\beta$-oxidation. Previously, AMPK activation has been reported to activate CaMKK $\beta$ and increase the expression of PGC-1 $\alpha$ [24]. In addition, more evidences also indicate AMPK might regulate the expression of PGC-1 $\alpha$ through Sirt1 [25] or p38 MAPK dependent signaling [14]. Surprisingly, in this study, we observed that AMPK regulates activity of PGC- $1 \alpha$ mainly through the p38 MAPK signaling pathway, but not Sirt1 signaling in mammary epithelial cells. The inconsistent results regarding the regulatory molecules that signal AMPK to PGC- $1 \alpha$ could partially be explained by tissue-specific regulation system. To our

\footnotetext{
(See figure on next page.)

Fig. $6 \beta$-TrCP mediating AMPK is involved in the ubiquitination degradation of PrIR. A-C Western blots of HC11 lysates for PrIR, $n=3$. As shown in the left part of $(\mathbf{A})$, the cells were treated with DMSO, Pitstop and EIPA to explore the effect of AMPK activation on the degradation of PrIR to explore the degradation mode of PrIR. In the right part of $(\mathbf{A})$, similar methods have also been used to explore the organelles involved in the degradation of PrIR. (B) and $(\mathbf{C})$ are the quantifications of protein expression in the above two experiments, respectively. (Pitstop: pinocytosis inhibitor, EIPA: endocytosis inhibitor, MG132: proteasome inhibitor, MA: lysosomal inhibitor) D-G Western blots of HC11 lysates for AMPK/B-TrCP/ PrIR pathway, $n=3$. In (D), bands were incubated with indicated proteins and Actin antibodies, $n=3$. Protein expressions of $\beta$ - TrCP, PrIR and milk proteins are shown in $(\mathbf{E}),(\mathbf{F})$ and $(\mathbf{G})$, respectively, $n=3$. $\mathbf{H}$ Immunoblot analysis of PrIR immunoprecipitates in HC11, probed for AMPK/Ub-PrIR pathway. After being cultured in the designated medium (all containing MA), cells were lysed by CHAPS lysis buffer, and lysate were not only used for immunoprecipitation to detect the ubiquitination of PrIR but also for WB to detect AMPK/PrIR pathway. I Immunoblot analysis of PrIR immunoprecipitates in $\mathrm{HC11}$, probed AMPK/ $\beta$-TrCP/Ub-PrIR pathway. After being transinfected by siRNA and cultured in the designated medium (all containing MA), cells were lysed by CHAPS lysis buffer, and lysate were not only used for immunoprecipitation to detect the ubiquitination of PrIR but also for WB to detect AMPK/PrIR pathway. In this figure, cells for WB were collected after $24 \mathrm{~h}$ incubation with indicated medium. All datas with error bars are averages \pm SEM. In histograms, the numbers above the column are the $p$-values marked as a range if significantly different $(P<0.05)$ and each small black dot represents a test value
} 
A

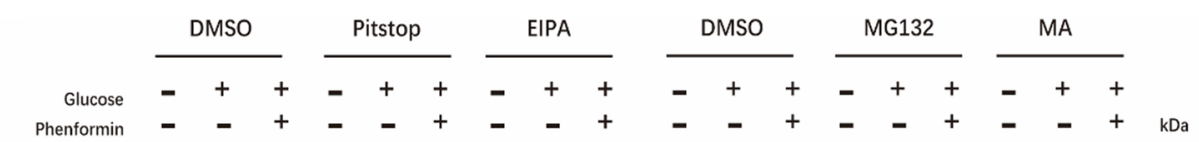

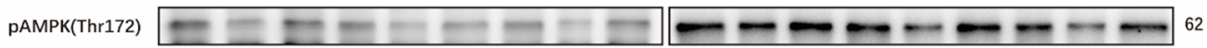

AMPK(total)

PrIR

Actin $=-\infty-\infty-\infty-\infty-\infty{ }^{42}$

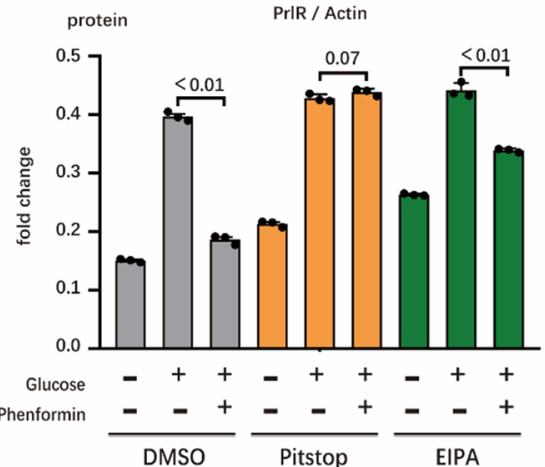

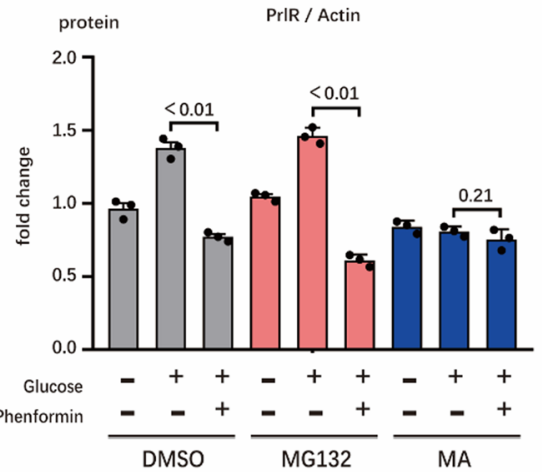

D

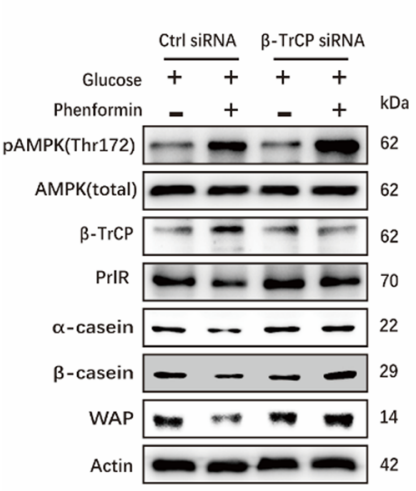

$\mathrm{H}$

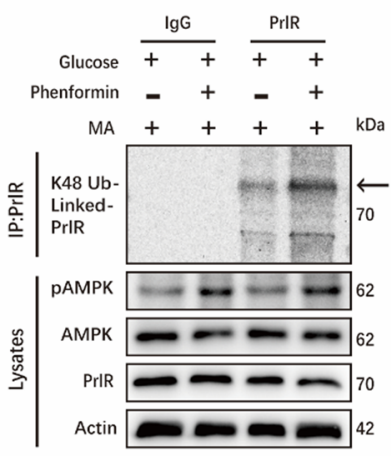

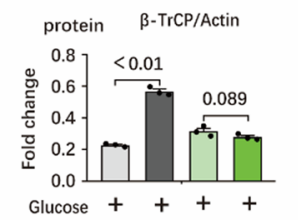

Glucose ++++

Phenformin $\underline{\mathbf{z}}+\mathbf{t}+$

$\mathrm{F}$ Ctrl siRNA $\overline{\beta-T \text { TrCP siRNA }}$

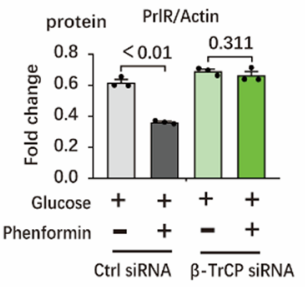

G

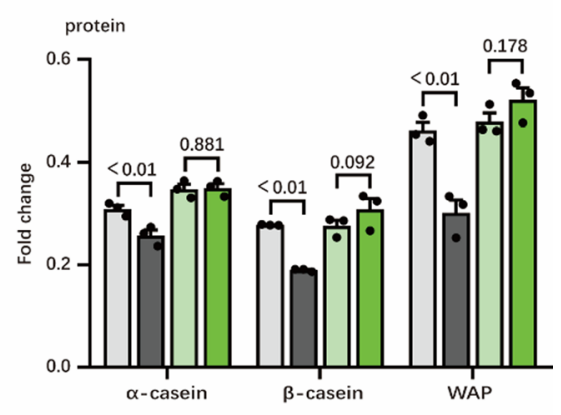

I

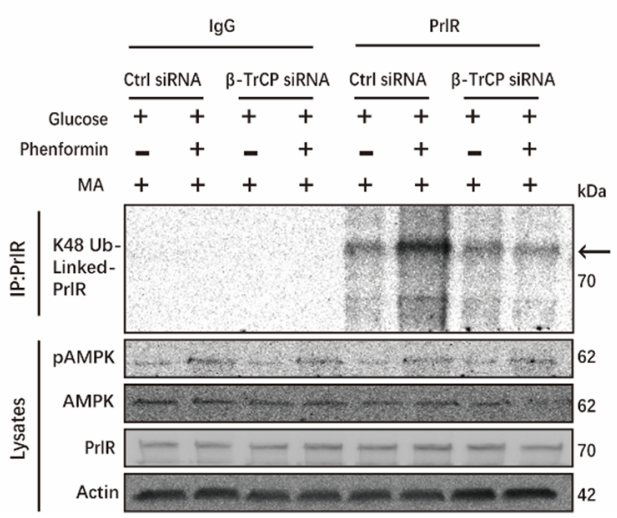

Fig. 6 (See legend on previous page.) 


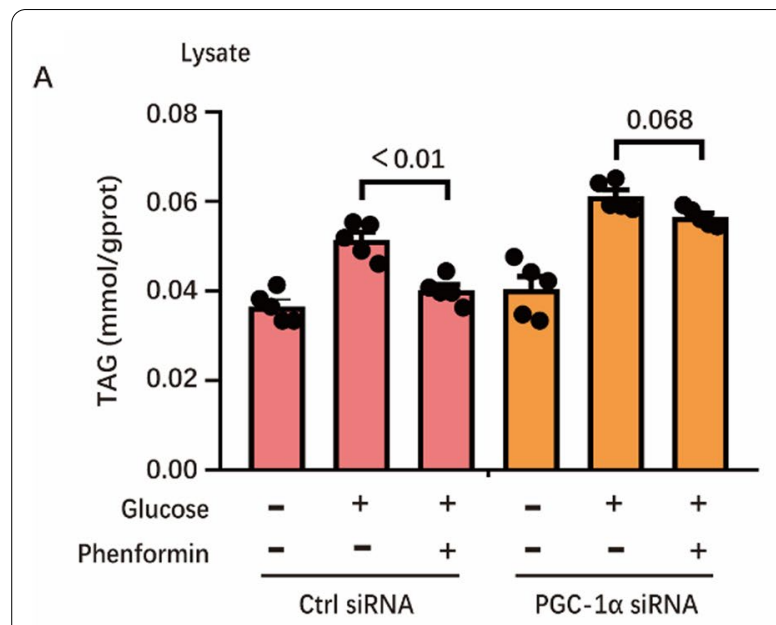

B

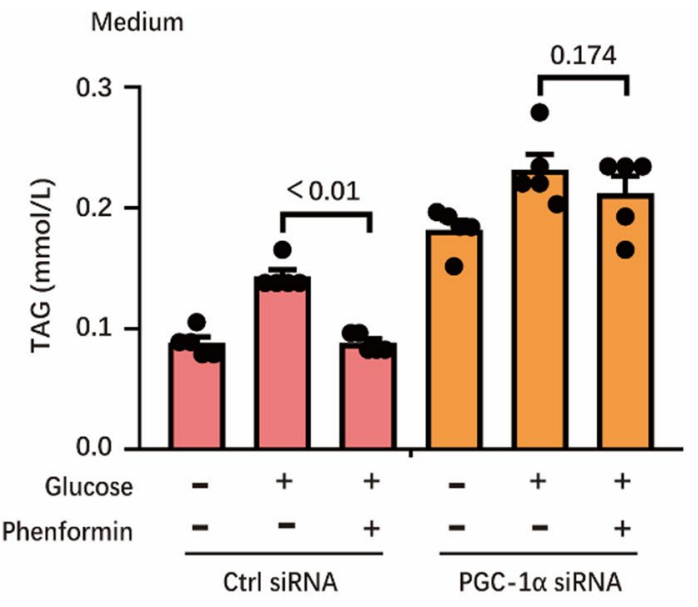

C
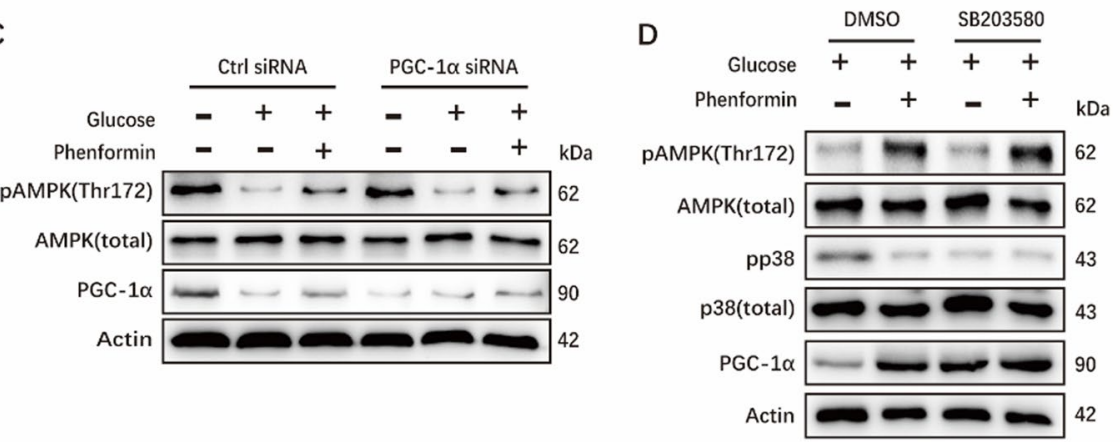

E protein PGC-1 $\alpha /$ Actin

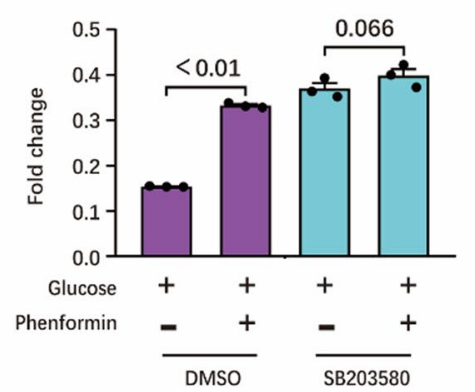

$\mathrm{F}$

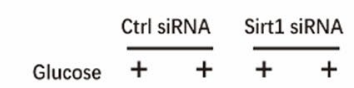

Phenformin - + - $+\mathrm{kDa}$

pAMPK(Thr172) 62

AMPK(total) $-\infty-62$

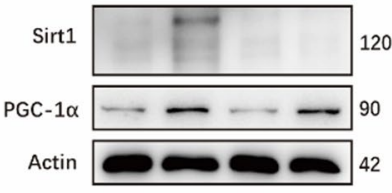

G

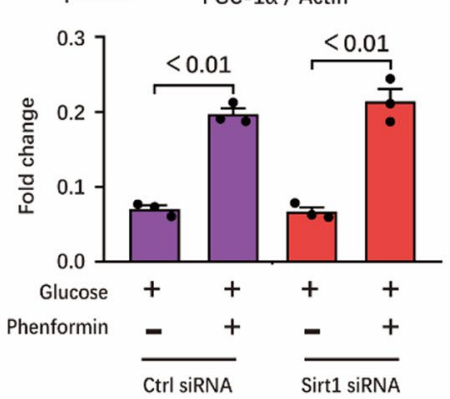

$\mathrm{H}$

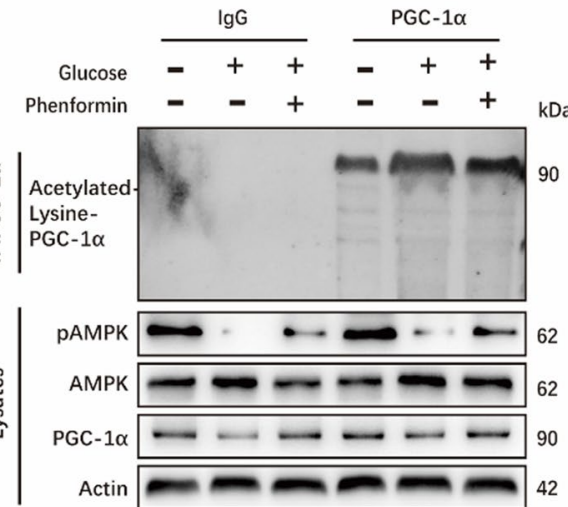

Fig. 7 Loss of PGC-1 a facilitates milk fat production due to its acetylation regulated by AMPK. A and B TAG concentration in cell (A) and medium (B), $n=5$. In the experiment, cells (transfected by siRNA in advance) for TAG determination were collected after $24 \mathrm{~h}$ incubation with $0 \mathrm{mM}$ glucose medium, $10 \mathrm{mM}$ glucose medium and (10 mM glucose + $300 \mu \mathrm{M}$ Phe) medium. CWestern blots of HC11 lysates for AMPK/PGC-1a signaling pathway, $n=3$. $\mathbf{D}$ and $\mathbf{E}$ Western blots of HC11 lysates for AMPK/p38/PGC-1 a signaling pathway, $n=3$. Cells were treated with $10 \mathrm{mM}$ glucose medium and (10 mM glucose + $300 \mu \mathrm{M}$ Phe) medium in the case of DMSO and SB203580 (p38 inhibitor) for $24 \mathrm{~h}$, respectively. In (D), bands were incubated with target proteins and Actin antibodies, $n=3$. Protein expressions of target proteins are shown in $(\mathbf{E}), n=3$. $\mathbf{F}$ and $\mathbf{G}$ Western blots of HC11 lysates for AMPK/Sirt1/PGC-1 a signaling pathway, $\mathrm{n}=3$. Cells were treated with $10 \mathrm{mM}$ glucose medium and (10 mM glucose $+300 \mu \mathrm{M}$ Phe) medium in the case of control-knockdown and Sirt1-knockdown for $24 \mathrm{~h}$, respectively. In (F), bands were incubated with target proteins and Actin antibodies, $n=3$. Protein expressions of target proteins are shown in $(\mathbf{G}), n=3$. $\mathbf{H}$ Immunoblot analysis of PGC-1 a immunoprecipitates in HC11, probed for acetylation of PGC-1 a. Cells were lysed by CHAPS lysis buffer, and lysate were not only used for immunoprecipitation to detect the acetylation of PGC-1 a but also for WB to detect AMPK/PGC-1 a pathway. In this figure, cells for TAG determination and WB were collected after $24 \mathrm{~h}$ incubation with indicated medium. All datas with error bars are averages \pm SEM. In histograms, the numbers above the column are the $p$-values marked as a range if significantly different $(P<0.05)$ and each small black dot represents a test value 


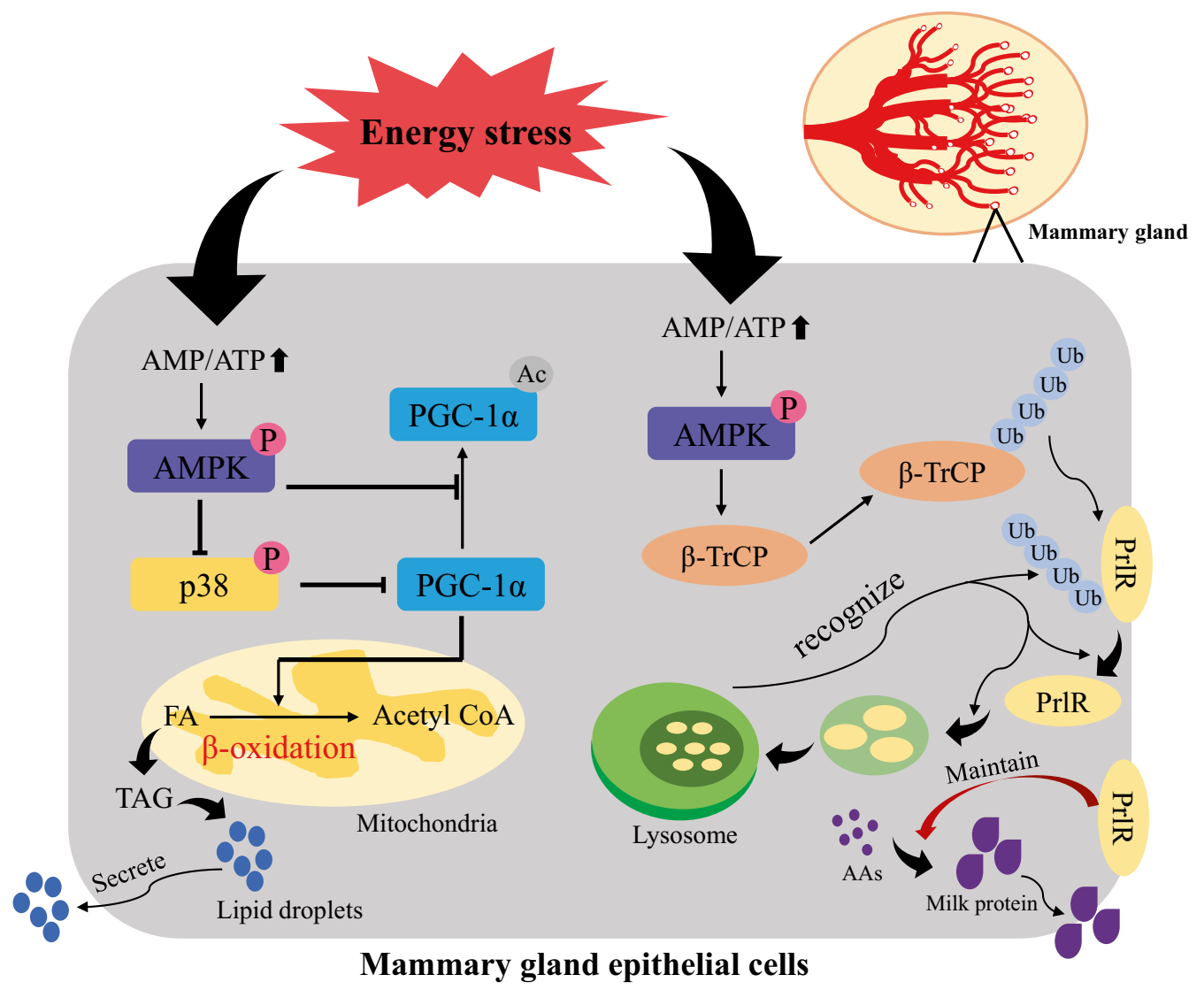

Fig. 8 Overall of AMPK's effect on milk fat and protein in HC11 cell line

knowledge, the activity of PGC-1 $\alpha$ is regulated by posttranslational modifications, including phosphorylation [26] and acetylation [27]. In subsequent experiments, we provided evidence that AMPK can inhibit the acetylation of PGC-1 $\alpha$. AMPK activation inhibits the activity of ACACA, which makes it difficult for acetyl-CoA to be converted into fatty acids. Thus, acetyl-CoA accumulation might eventually lead to the inhibition of the acetylation reaction [28]. As a non-histone protein, the molecular mechanism of acetylation of PGC- $1 \alpha$ warrants additional work.

\section{Conclusions}

In summary, we confirmed the hypothesis that AMPK regulates the production of milk protein and fat in the mammary gland by regulating the degradation of PrlR and the acetylation of PGC- $1 \alpha$, respectively (Fig. 8). Although some mechanisms require further verification, it is foreseeable that this mechanism can be utilized to provide new possibilities and inspiration for the regulation of milk synthesis.

\section{Abbreviations}

AMPK: AMP-activated protein kinase; mTORC1: Mammalian target of rapamycin complex 1; PrIR: Prolactin receptor; $\beta-\operatorname{TrCP} ; \beta$-Transducin repeat-containing protein; PGC-1a: Peroxisome proliferator-activated receptor gamma coactivator-1 alpha; FBP: Fructose-1,6-bisphosphate; FA: Fatty acid; TAG: Triacylglycerol; ACACA: Acetyl-coA carboxylase alpha; SREBP1c: Sterol regulatory elementbinding protein 1c; S6K1: S6 kinase 1; 4EBP1: 4E binding protein 1; pMECs: Porcine mammary gland epithelial cells; TSC2: Tuberin 2.

\section{Supplementary Information}

The online version contains supplementary material available at https://doi. org/10.1186/s12964-022-00830-6.

Additional file 1. Fig. S1. Glucose increases milk fat production but inhibits AMPK. (A) Oil red O staining images of pMECs. Scale bars are $100 \mu \mathrm{m}$.

(B and C) Western blots of pMECs lysates for critical fat synthesis genes. (B) are representative western-blotting bands hybridized with target proteins including FASN, ACACA, FABP3, DGAT1, SREBP1 and Actin antibodies, $n=3$. (C) is the result of analyzing the WB bands, $n=3$. (D) Ratio of ATP and $A D P, n=3$. $H C 11$ cells were collected after $24 \mathrm{~h}$ incubation with $0 \mathrm{mM}$ and $10 \mathrm{mM}$ glucose mediums. (E and F) Western blots analysis of HC11 lysates for AMPK signaling pathway, $\mathrm{n}=3$. Cells were collected after $24 \mathrm{~h}$ incubation with $0 \mathrm{mM}$ and $10 \mathrm{mM}$ glucose mediums. Fig. S2. Inhibition of AMPK still promotes the synthesis of milk fat and protein in the absence of glucose. (A) Western blots analysis of HC11 lysates for AMPK signaling pathway. Cells were collected after $24 \mathrm{~h}$ incubation with $0 \mathrm{mM}$ glucose medium, $10 \mathrm{mM}$ glucose medium, (10 mM glucose $+\mathrm{CC}$ ) medium, $2 \mathrm{mM}$ glucose medium and (2 mM glucose $+\mathrm{CC}$ ) medium. (B and C) TAG TAG 
concentration in cell (B) and medium (C), $n=6$. (D and E) Western blots of HC11 lysates for critical protein synthesis genes. (D) are representative western-blotting bands hybridized with target proteins including $a$-casein, $\beta$-casein, WAP and Actin antibodies, $n=3$. (E) is the result of analyzing the WB bands, $n=3$. Fig. S3. AMPK activates the mTORC1/ S6K1/4EBP1 pathway in both HC11 and pMECs. (A and B) Western blots analysis of $\mathrm{HC} 11$ lysates for mTORC1/S6K1/4EBP1 signaling pathway, $\mathrm{n}=3$. Cells were collected after $24 \mathrm{~h}$ incubation with $0 \mathrm{mM}$ glucose medium, $10 \mathrm{mM}$ glucose medium, (10 mM glucose +AICAR) medium and (10 $\mathrm{mM}$ glucose +Phe) medium. (C and D) Western blots analysis of pMECs lysates for AMPK/mTORC1 signaling pathway, $\mathrm{n}=3$. (E and F) Western blots analysis of HC11 lysates for AMPK/mTORC1 signaling pathway. Cells were collected after $24 \mathrm{~h}$ incubation with $0 \mathrm{mM}$ glucose medium, $2 \mathrm{mM}$ glucose medium and ( 2 mM glucose $+\mathrm{CC}$ ) medium, $n=3$. Fig. $\mathbf{S 4}$. $\mathrm{mTORC} 1$ up-regulates synthesis of milk fat and protein in $\mathrm{HC} 11$. (A and B) Western blots analysis of $\mathrm{HC} 11$ lysates for mTORC1/S6K1/4EBP1 signaling pathway, $\mathrm{n}=3$. (C) Oil red $\mathrm{O}$ staining images of $\mathrm{HC} 11$. Scale bars are $50 \mu \mathrm{m}$. (D and E) TAG concentration in cell (D) and medium (E), $n=4$. (F-H) Western blots and real time PCR of $\mathrm{HC} 11$ lysates for critical fat synthesis genes. (F) are representative western-blotting bands hybridized with target proteins including FASN, ACACA, FABP3, DGAT1, SREBP1 and Actin antibodies, $n=3$. $(G)$ is the result of analyzing the WB bands and $(H)$ represents datas from real-time PCR, $n=3$. (I-K) Western blots and real time PCR of HC11 lysates for critical protein synthesis genes. (I) are representative western-blotting bands hybridized with target proteins including a-casein, $\beta$-casein, WAP and Actin antibodies, $n=3$. $(J)$ is the result of analyzing the WB bands and $(K)$ represents datas from real-time $P C R, n=3$. In this figure, cells for oil red O staining, TAG determination and WB were collected after $24 \mathrm{~h}$ incubation with $0 \mathrm{mM}$ glucose medium, $10 \mathrm{mM}$ glucose medium and (10 $\mathrm{mM}$ glucose +rapamycin) medium and cells for real-time PCR are $12 \mathrm{~h}$. All datas with error bars are averages \pm SEM. In histograms, the numbers above the column are the $p$-values marked as a range if significantly different $(P<0.05)$ and each small white dot represents a test value. Fig. S5. AMPK is involved in regulating the activity of amino acid transporters in HC11. (A) GSEA showing enrichment of amino acid transport across plasma membrane in $\mathrm{HC} 11$ differentially expressed genes. The graph (left) shows the result of the control group-vs-glucose group and another graph (right) shows glucose group-vs-PHE group. (B and C) (B) is heatmap analysis of up-regulated (red) or down-regulated genes (blue) in $\mathrm{HC} 11$, $n=3$. The tested genes are amino acid transporters selected from the GSEA gene set (shown in the figure). (C) is the result of real-time $P C R, n=3$. ( $D$ and $E$ ) (D) is heatmap analysis of up-regulated (red) or down-regulated genes (blue) in $\mathrm{HC1} 1, \mathrm{n}=3$. The tested genes are typical aminotransferases (shown in the figure). (E) is the result of real-time $P C R, n=3$. In this figure, cells for RNA-seq and real-time PCR were collected after $12 \mathrm{~h}$ incubation with $0 \mathrm{mM}$ glucose medium, $10 \mathrm{mM}$ glucose medium and $(10 \mathrm{mM}$ glucose + Phe) medium. All datas with error bars are averages \pm SEM. In histograms, the numbers above the column are the $p$-values marked as a range if significantly different $(P<0.05)$ and each small white dot represents a test value.

\section{Acknowledgements}

We thank the National Natural Science Foundation of the P.R. of China, Guangdong Basic and Applied Basic Research Foundation, Science and Technology Program of Guangzhou.

\section{Authors' contributions}

SZ and FC designed the research. ZW took the lead in performing all experiments with critical help of QL, SY, TZ and JS, and conducted the statistical analysis. ZW and SZ wrote the manuscript. SZ, FC and WG conducted the final editing. SZ supervised the study throughout. All authors read and approved the final manuscript.

\section{Funding}

This study was financially supported by the National Key R\&D Program of China (2021YFD1300700), Guangdong Basic and Applied Basic Research Foundation (No. 2021A1515010440), Science and Technology Program of Guangzhou (No. 202102020056).

\section{Availability of data and materials}

The data analyzed during the current study are available from the corresponding author on request.

\section{Declarations}

Ethics approval and consent to participate

Not applicable.

\section{Consent for publication}

Not applicable.

\section{Competing interests}

The authors declare that they have no competing interests.

\section{Author details}

${ }^{1}$ Guangdong Province Key Laboratory of Animal Nutrition Control, College of Animal Science, South China Agricultural University, Guangzhou 510642, China. ${ }^{2}$ College of Animal Science and National Engineering Research Center for Breeding Swine Industry, South China Agricultural University, Guangzhou 510642, China. ${ }^{3}$ Guangdong Laboratory for Lingnan Modern Agriculture, South China Agricultural University, Guangzhou, China.

Received: 10 December 2021 Accepted: 9 January 2022

Published online: 05 March 2022

\section{References}

1. Wu Z, Heng J, Tian M, Song H, Chen F, Guan W, et al. Amino acid transportation, sensing and signal transduction in the mammary gland: key molecular signalling pathways in the regulation of milk synthesis. Nutr Res Rev. 2020;33:287-97. https://doi.org/10.1017/s0954422420000074.

2. Zhang CS, Hawley SA, Zong Y, Li M, Wang Z, Gray A, et al. Fructose-1,6-bisphosphate and aldolase mediate glucose sensing by AMPK. Nature. 2017;548:112-6. https://doi.org/10.1038/nature23275.

3. McFadden JW, Corl BA. Activation of AMP-activated protein kinase (AMPK) inhibits fatty acid synthesis in bovine mammary epithelial cells. Biochem Biophys Res Commun. 2009;390:388-93. https://doi.org/10. 1016/j.bbrc.2009.09.017.

4. Burgos SA, Kim JJ, Dai M, Cant JP. Energy depletion of bovine mammary epithelial cells activates AMPK and suppresses protein synthesis through inhibition of mTORC1 signaling. Horm Metab Res. 2013;45:183-9. https:// doi.org/10.1055/s-0032-1323742.

5. Zhang MC, Zhao SG, Wang SS, Luo CC, Gao HN, Zheng N, et al. d-Glucose and amino acid deficiency inhibits casein synthesis through JAK2/STAT5 and AMPK/mTOR signaling pathways in mammary epithelial cells of dairy cows. J Dairy Sci. 2018;101:1737-46. https://doi.org/10.3168/jds. 2017-12926.

6. Wu Z, Tian M, Heng J, Chen J, Chen F, Guan W, et al. Current evidences and future perspectives for AMPK in the regulation of milk production and mammary gland biology. Front Cell Dev Biol. 2020;8:530. https://doi. org/10.3389/fcell.2020.00530.

7. Abu-Elheiga L, Brinkley WR, Zhong L. The subcellular localization of acetyl-CoA carboxylase 2. Proc Natl Acad Sci. 2000;97:1444-9. https://doi. org/10.1073/pnas.97.4.1444.

8. Li N, Zhao F, Wei C, Liang M, Zhang N, Wang C, et al. Function of SREBP1 in the milk fat synthesis of dairy cow mammary epithelial cells. Int J Mol Sci. 2014;15:16998-7013. https://doi.org/10.3390/ijms150916998.

9. Xu HF, Luo J, Zhao WS, Yang YC, Tian HB, Shi HB, et al. Overexpression of SREBP1 (sterol regulatory element binding protein 1) promotes de novo fatty acid synthesis and triacylglycerol accumulation in goat mammary epithelial cells. J Dairy Sci. 2016;99:783-95. https://doi.org/10.3168/jds. 2015-9736.

10. Che L, Xu M, Gao K, Zhu C, Wang L, Yang X, et al. Valine increases milk fat synthesis in mammary gland of gilts through stimulating AKT/MTOR/ SREBP1 pathwayt. Biol Reprod. 2019;101:126-37. https://doi.org/10.1093/ biolre/ioz065. 
11. Jiang W, Zhu Z, Thompson HJ. Dietary energy restriction modulates the activity of AMP-activated protein kinase, Akt, and mammalian target of rapamycin in mammary carcinomas, mammary gland, and liver. Cancer Res. 2008;68:5492-9. https://doi.org/10.1158/0008-5472.Can-07-6721.

12. Zhou G, Myers R, Li Y, Chen Y, Shen X, Fenyk-Melody J, et al. Role of AMPactivated protein kinase in mechanism of metformin action. J Clin Invest. 2001;108:1167-74. https://doi.org/10.1172/jci13505.

13. Gan L, Yan J, Liu Z, Feng M, Sun C. Adiponectin prevents reduction of lipid-induced mitochondrial biogenesis via AMPK/ACC2 pathway in chicken adipocyte. J Cell Biochem. 2015;116:1090-100. https://doi.org/ 10.1002/jcb.25064.

14. Chaube B, Malvi P, Singh SV, Mohammad N, Viollet B, Bhat MK. AMPK maintains energy homeostasis and survival in cancer cells via regulating p38/PGC-1a-mediated mitochondrial biogenesis. Cell Death Discov. 2015;1:15063. https://doi.org/10.1038/cddiscovery.2015.63.

15. Yu Y, Zhao Y, Teng F, Li J, Guan Y, Xu J, et al. Berberine improves cognitive deficiency and muscular dysfunction via activation of the AMPK/SIRT1/ PGC-1a pathway in skeletal muscle from naturally aging rats. J Nutr Health Aging. 2018;22:710-7. https://doi.org/10.1007/s12603-018-1015-7.

16. Moe PW. Energy metabolism of dairy cattle. J Dairy Sci. 1981;64:1120-39. https://doi.org/10.3168/jds.S0022-0302(81)82692-6.

17. Varghese B, Barriere $H$, Carbone CJ, Banerjee A, Swaminathan G, Plotnikov $A$, et al. Polyubiquitination of prolactin receptor stimulates its internalization, postinternalization sorting, and degradation via the lysosomal pathway. Mol Cell Biol. 2008;28:5275-87. https://doi.org/10.1128/mcb. 00350-08.

18. Li Y, Kumar KG, Tang W, Spiegelman VS, Fuchs SY. Negative regulation of prolactin receptor stability and signaling mediated by SCF(beta-TrCP) E3 ubiquitin ligase. Mol Cell Biol. 2004;24:4038-48. https://doi.org/10.1128/ mcb.24.9.4038-4048.2004.

19. Wu W, Wang S, Liu Q, Shan T, Wang X, Feng J, et al. AMPK facilitates intestinal long-chain fatty acid uptake by manipulating CD36 expression and translocation. FASEB J. 2020;34:4852-69. https://doi.org/10.1096/f.20190 1994R.

20. Zhang R, Huang SY, Li KKW, Li YH, Hsu WH, Zhang GJ, et al. Dual degradation signals destruct GLI1: AMPK inhibits GLI1 through $\beta$-TrCP-mediated proteasome degradation. Oncotarget. 2017;8:49869-81. https://doi.org/ 10.18632/oncotarget.17769.

21. Handschin C, Spiegelman BM. Peroxisome proliferator-activated receptor gamma coactivator 1 coactivators, energy homeostasis, and metabolism. Endocr Rev. 2006;27:728-35. https://doi.org/10.1210/er.2006-0037.

22. Inagaki T, Dutchak P, Zhao G, Ding $X$, Gautron L, Parameswara $V$, et al. Endocrine regulation of the fasting response by PPARalpha-mediated induction of fibroblast growth factor 21. Cell Metab. 2007;5:415-25. https://doi.org/10.1016/j.cmet.2007.05.003.

23. Thomson DM, Winder WW. AMP-activated protein kinase control of fat metabolism in skeletal muscle. Acta Physiol (Oxf). 2009;196:147-54. https://doi.org/10.1111/j.1748-1716.2009.01973.x.

24. Iwabu M, Yamauchi T, Okada-Iwabu M, Sato K, Nakagawa T, Funata M, et al. Adiponectin and AdipoR1 regulate PGC-1alpha and mitochondria by $\mathrm{Ca}(2+)$ and AMPK/SIRT1. Nature. 2010;464:1313-9. https://doi.org/10. 1038/nature08991.

25. Iwabu M, Yamauchi T, Okada-Iwabu M, Sato K, Nakagawa T, Funata M, et al. Adiponectin and AdipoR1 regulate PGC-1 a and mitochondria by Ca2+ and AMPK/SIRT1. Nature. 2010;464:1313-9. https://doi.org/10. 1038/nature08991.

26. Li L, Mühlfeld C, Niemann B, Pan R, Li R, Hilfiker-Kleiner D, et al. Mitochondrial biogenesis and PGC-1 a deacetylation by chronic treadmill exercise: differential response in cardiac and skeletal muscle. Basic Res Cardiol. 2011;106:1221-34. https://doi.org/10.1007/s00395-011-0213-9.

27. Jäger S, Handschin C, St-Pierre J, Spiegelman BM. AMP-activated protein kinase (AMPK) action in skeletal muscle via direct phosphorylation of PGC-1alpha. Proc Natl Acad Sci U S A. 2007;104:12017-22. https://doi.org/ 10.1073/pnas.0705070104.

28. Mews P, Donahue G, Drake AM, Luczak V, Abel T, Berger SL. Acetyl-CoA synthetase regulates histone acetylation and hippocampal memory. Nature. 2017;546:381-6. https://doi.org/10.1038/nature22405.

\section{Publisher's Note}

Springer Nature remains neutral with regard to jurisdictional claims in published maps and institutional affiliations.
Ready to submit your research? Choose BMC and benefit from:

- fast, convenient online submission

- thorough peer review by experienced researchers in your field

- rapid publication on acceptance

- support for research data, including large and complex data types

- gold Open Access which fosters wider collaboration and increased citations

- maximum visibility for your research: over 100M website views per year

At BMC, research is always in progress.

Learn more biomedcentral.com/submissions 